\title{
BRANDING IN A HYPERCONNECTED WORLD: REFOCUSING THEORIES AND RETHINKING BOUNDARIES
}

\author{
Vanitha Swaminathan \\ Thomas Marshall Professor of Marketing \\ Katz Graduate School of Business \\ University of Pittsburgh \\ Pittsburgh, PA \\ email: vanitha@katz.pitt.edu
}

\author{
Alina Sorescu \\ Paula and Steve Letbetter ' 70 Professor of Marketing \\ Mays Business School \\ Texas A\&M University \\ College Station, TX \\ email: asorescu@tamu.edu \\ Jan-Benedict E.M. Steenkamp \\ C. Knox Massey Distinguished Professor of Marketing \\ Kenan-Flagler Business School \\ UNC-Chapel Hill \\ Chapel Hill, NC \\ email:JBS@unc.edu \\ Thomas Clayton Gibson O'Guinn \\ Professor and Irwin Maier Distinguished Chair in Business \\ Chair, Marketing Department \\ Professor of Sociology \\ University of Wisconsin \\ Madison, WI \\ email: thomas.oguinn@wisc.edu \\ Bernd Schmitt \\ Robert D. Calkins Professor of International Business \\ Columbia Business School \\ 510 Uris Hall \\ New York, NY \\ email: bhs1@gsb.columbia.edu
}




\section{Branding in a Hyperconnected World: Refocusing Theories and Rethinking Boundaries}

\section{ABSTRACT}

Technological advances have resulted in a hyperconnected world, requiring a reassessment of branding research from the perspectives of firms, consumers, and society. Brands are shifting away from single ownership to shared ownership, as heightened access to information and people is allowing more stakeholders to cocreate brand meanings and experiences alongside traditional brand owners and managers. Moreover, hyperconnectivity has allowed existing brands to expand their geographic reach and societal roles, while new types of branded entities (ideas, people, places, and organizational brands) are further stretching the branding space. To help establish a new branding paradigm that accounts for these changes, the authors address the following questions: (1) What are the roles and functions of brands? (2) How is brand value (co)created? and (3) How should brands be managed? Throughout the article the authors also identify future research issues that require scholarly attention, with the aim to align branding theory and practice with the realities of a hyperconnected world.

Keywords: branding, hyperconnectivity, brand management, brand equity 
Over the course of a century, branding has moved from an occasionally studied activity to a major concern for both business and society. Traditional commercial brands are omnipresent and compete for consumer attention with newer branded entities, such as platform brands (e.g., Airbnb), direct-toconsumer brands (e.g., Warby Parker), smart brands (e.g., Google Nest), idea brands (e.g., \#MeToo), and person brands (e.g., Kim Kardashian). The manner in which consumers interact with brands is also changing due to the rise of digitally native brands, the ubiquitous access to information and products via digital and mobile channels, and the broad availability of smart, connected devices.

To inspire next-generation conceptual and empirical work on branding, this article examines how existing perspectives need to be refocused and rethought to address the realities of contemporary society. We examine broader types of entities, ranging from smart branded devices and entities that operate in networks of brands to ideas and person brands. We also investigate the blurring of brand boundaries brought about by technology-induced hyperconnectivity. In doing so, we expand on new frontiers in branding research and argue that these topics need to be a larger part of research agendas.

Our review of the marketing literature suggests that extant theoretical perspectives-from the vantage points of the firm, the consumer, and society—have resulted in certain models and assumptions that may no longer be adequate or sufficient in a hyperconnected world. The concept of hyperconnectivity refers to the proliferation of networks of people, devices, and other entities, as well as the continuous access to other people, machines, and organizations, regardless of time or location (Fredette et al. 2012; Quan-Haase and Wellman 2005). In this environment, information is always accessible and abundant, search costs are low, goods and services from across geographic boundaries are easier to reach than ever, and firms may no longer be the primary source of information about brands.

Hyperconnectivity has led to two major changes in branding. First, brands are shifting away from single to shared ownership, as heightened access to information and people is allowing more 
stakeholders to cocreate brand experiences and brand meanings alongside traditional brand owners (or entities who market the brand). We call this phenomenon the "blurring of branding boundaries." Second, hyperconnectivity has allowed existing brands to expand their geographic reach and societal roles, while new types of branded entities are further stretching the branding space, which constitutes a "broadening of branding boundaries."

In this article, we elaborate on the consequences of hyperconnectivity on the "blurring" and "broadening" of branding boundaries. We focus both on challenges and opportunities that brands face in a hyperconnected environment. We first briefly review three core perspectives that have underscored traditional branding research and then examine the implications of this expanded view of brands through three fundamental questions: (1) What are the roles and functions of brands? (2) How do brands (co)create value? and (3) How should brands be managed? We provide initial answers to these questions and we outline areas of inquiry for future research.

\section{Key Theoretical Perspectives in the Branding Literature}

Many conceptualizations of brands have been proposed across various domains of inquiry, each with its own particular focus. We distinguish three theoretical perspectives (firm, consumer, and society) and two approaches within each perspective. The firm perspective views brands as assets and examines the various functions and roles that brands serve for firms, both strategically and financially. The consumer perspective views brands as signals (economic approach) and mental knowledge cues (psychological approach). The society perspective presents brands in societal and cultural contexts affecting individual consumers both directly and indirectly through social forces, structures and institutions. The sociology of brands applies to all manner of commercial and noncommercial entities (e.g., ideas, persons). We briefly introduce each perspective in this section, while acknowledging the overlap and spillovers of knowledge across various approaches used in the literature. One source of 
this overlap comes from the nested structure that underlies how these perspectives relate to each other. For example, societal macroenvironments host institutions (including the firm) that, in turn, interact to shape consumer-level outcomes.

\section{Firm Perspective}

Strategic approach. Key issues examined in this approach include the development and implementation of brand identity; positioning, targeting, launch, and growth of brands; brand portfolio architecture; and management of brands across geographic boundaries (Kapferer 2012; Steenkamp 2017). Topics studied range from how to effectively construct and manage brand portfolios (Morgan and Rego 2009) to how to extend brands into new categories, as new brands, endorsers, subbrands, descriptors, product brands, umbrella brands, and branded differentiators (Völckner and Sattler 2006). Marketing alliances of various types, including cobranding alliances and collaboration with customers, along with brand acquisitions and divestitures are strategic challenges and opportunities that have also been addressed in this literature.

Financial approach. Researchers leveraging a financial approach to branding have focused mainly on measuring the effect of brand equity and branding actions on the stock market value of firms. Specifically, one research stream has focused on demonstrating the relevance of consumer-based brand equity (Madden, Fehle, and Fournier 2006; Mizik and Jacobson 2008; Rego, Billett, and Morgan 2009), while another stream has focused on measuring the stock market impact of corporate actions, such as brand extensions (Lane and Jacobson 1995), brand and marketing alliances (Cao and Sorescu 2013; Swaminathan and Moorman 2009), brand acquisitions (Bahadir, Bharadwaj, and Srivastava 2008; Wiles, Morgan, and Rego 2012), and brand architecture decisions (Hsu, Fourier, and Srinivasan 2016). Keller and Lehmann (2006) provide an overview of research that has examined the impact of brand actions on a variety of financial (and nonfinancial) firm outcomes.

\section{Consumer Perspective}


Economic approach. Firms tend to know more than consumers about the quality of their brand. This information asymmetry has given rise to a field of study that treats brands as market signals (Erdem and Swait 1998). The brand extension literature has leveraged the information asymmetryreducing role of brands to determine (1) how a multiproduct firm can brand a new product, (2) the relationship between the reputation of the new product and that established by the firm in other markets, and (3) the perceived quality of a new product (Erdem 1998; Wernerfelt 1988).

Psychological approach. Schmitt's (2012) “consumer-psychology-of-brands” model summarizes the key concepts of the psychological approach, which proposes that brand equity resides in the minds of customers. Brand knowledge, which is the mental representation of brand awareness (recall and recognition) and brand image (types, favorability, strength, and uniqueness of brand associations), constitutes the key construct for conceptualizing and measuring brand equity from the customer's point of view (Keller 1993). Other mental representations include affect and emotions, leading to constructs such as brand trust (Rajavi, Kushwaha, and Steenkamp 2019), emotional brand attachment (Thomson, MacInnis, and Park 2005), brand coolness (Warren et al. 2019), and even brand love (Batra, Ahuvia, and Bagozzi 2012). This perspective also includes brand experiences and defines them as including sensory, affective, and intellectual impressions but also behavioral actions toward brands (Brakus, Schmitt, and Zarantonello 2009; Schmitt, Brakus, and Zarantonello 2015).

\section{Society Perspective}

Sociological approach. Researchers approaching brands from a sociological perspective focus mainly on brands as portable containers of meaning that are shaped by institutions and collectives from the time the brand is conceived, produced, and marketed, through the post-purchase stage (O'Guinn, Muñiz, and Paulson 2018). Sociological models are typically dynamic and recursive. Sociological scholars do not view brands as static entities or as mere information sources or knowledge structures; rather, they have a keen interest in how brand meanings are generated, changed, and dynamically 
reinvented. An important notion in this literature is brand community, a nongeographic space in which admirers of a brand connect with one another and demonstrate all three necessary distinctions of community: consciousness of kind, rituals and traditions, and moral obligation (Muñiz and O'Guinn 2001).

Cultural approach. Both sociologists and anthropologists study culture, and their work in branding and marketing meaningfully intersects. One of the main insights from this research is that branded goods, as cultural meaning producers, enhance consumers' lives (Miller 2010). Probably the best-known perspective on how brands become popular through their production of cultural capital is the widespread adaptation of Bourdieu (1986) in consumer culture theory (Thompson and Arnould 2005). Among other things, consumer culture theory addresses the dynamic relationships among consumer actions, the marketplace, and cultural meanings. Research in this stream focuses on how iconic brands (Holt 2004), or brands infused with cultural referents (Cayla and Eckhardt 2008), contribute to culturally-bound consumption practices (Epp, Schau, and Price 2014). Invoking the same dynamic, these scholars demonstrate how anti-brand activists and other cultural intermediaries can introduce a competing set of brand meanings (e.g., doppelgänger brand images) that can significantly influence consumer behavior and market creation (Giesler 2012; Thompson, Rindfleisch, and Arsel 2006).

We summarize key insights from each perspective (firm, consumer, and society) in Table WA1 in the Web Appendix. As this table is structured by sub-streams of research, it also illustrates how several of the theoretical perspectives have helped advance each area of inquiry. We next leverage these perspectives into a discussion of how the boundaries of branding have blurred and broadened in response to changes occurring in a hyperconnected environment. We revisit them later in the article as we advocate a multidisciplinary approach to address current opportunities and challenges in the branding domain. 


\section{Boundaries of Branding in the Era of Hyperconnectivity}

We noted that the hyperconnected world is characterized by networks of people, devices, and other entities that are continuously interacting and exchanging information. Several aspects of hyperconnectivity are relevant to branding research and management (Tybout and Calkins 2019). We highlight three aspects: (1) Information availability and speed of information dissemination; (2) Networks of people and devices, and the growth of platforms; and (3) Device-to-device connectivity. We next examine each of these in greater detail.

\section{Information Availability and Speed of Information Dissemination}

The scale of information availability and the speed of information dissemination have grown exponentially as technology that connects people and devices has become widely available and more affordable. The broad and fast access to information calls into question foundational assumptions of several of the theoretical perspectives we discussed in the previous section. For example, high search costs and information asymmetry have been the core assumptions of the economic view of brands as signaling mechanisms (Erdem and Swait 1998; Wernerfelt 1988). But brands may no longer serve as primary signals of quality in an environment in which search costs are low and information asymmetry is reduced by various stakeholders who abundantly share opinions about brands across their networks.

Because access to information is much easier in a hyperconnected world, consumers need to expend less effort in learning information about brands. Models of memory activation and learning need to be updated to account for consumers' increased reliance on external sources of information as opposed to information that is retrieved from memory. Moreover, the sheer volume of external information can lead to information overload - a situation in which not all communication input can be processed and used (Broniarczyk and Griffin 2014; Schwartz 2004). The velocity and volume of information that consumers are exposed to, along with the potential information overload that results 
from it, reduce brands' ability to capture the attention of their target segment (Lurie 2004), which calls for a reexamination of models of attention.

\section{Networks of People and Devices, and Growth of Platforms}

The rise of networks of people and devices and the development of platform technology have led to an environment in which brands and their meanings are cocreated. Firms are not the only entities that can disseminate branded information quickly and broadly - they now compete with other stakeholders who can do so just as easily (e.g., Libai et al. 2010). Brand conversations are happening online, and consumers may listen to their peers or to online influencers just as much as, if not more than they listen to branded messages generated by firms. A growing stream of research is documenting the effect of this loss of control on brand meaning (Chevalier and Mayzlin 2006; Fournier and Avery 2011) and brand experiences (Perren and Kozinets 2018).

\section{Device-to-Device Connectivity}

Device-to-device connectivity has impacted brands in several ways. First, branded experiences are significantly more complex in an environment when consumers can access the brand via multiple channels that seamlessly connect with each other. Second, the heightened connectivity among devices has led to brands themselves being integral components of networks of smart products that are populating the Internet of Things (Hoffman and Novak 2017). This again calls into question what entities contribute to brand meaning and associations, how these associations can be managed, and to what extent consumers anthropomorphize branded products that communicate with other products.

\section{Blurring and Broadening of Branding in a Hyperconnected World}

We next discuss how these manifestations of hyperconnectivity have resulted in a "blurring" and "broadening" of branding boundaries. We reexamine these issues as we highlight the changing roles and functions of brands, how they create value, and how they should be managed. 


\section{Blurring of Branding}

Traditionally, brand management methods were designed for a world in which consumers were exposed to (and influenced by) firm-controlled television, print, and radio advertising (Aaker 1996). Today, as information becomes available widely across multiple channels, consumers' attention is scattered across many media and channels, forcing a multitude of branded entities to compete to gain consumers' awareness and potentially to form an emotional connection. As brand meaning is increasingly co-created, it is even sometimes hijacked by consumers and firm partners (Fournier and Avery 2011; Wipperfürth 2005).

Beyond the cocreation of brand meaning, brand stakeholders (ranging from customers and employees, to firm partners, to communities, to society at large) are increasingly shaping various aspects of product and marketing-mix activities. For example, firms that use a platform-based business model often bring together partners that help cocreate the entire brand experience. Alternatively, firms that allow their products to interact with voice-controlled smart devices such as Amazon's Echo or with home automation hubs such as Wink Hub are also relinquishing some control, as brand associations can transfer to and from these partner brands to the focal one with potentially serious consequences for brands' performance and business survival (Wu, Chen, and Dou 2017). The blurring of brand boundaries is a key consequence of the rise of the sharing economy, which "offers temporary access as an alternative to permanent ownership" (Eckhardt et al. 2019, p.2), and which has expanded the role of customers to span both the demand and the supply side.

\section{Broadening of Branding}

As marketers are losing some control over the meaning consumers associate with brands, more brand-related stakeholders are involved in the shaping brand associations. Entities other than corporations - such as ideas and persons - are becoming more systematic in their branding efforts (Fournier and Eckhart 2019; Thomson 2006), as hyperconnectivity has allowed them to easily reach 
multiple stakeholders around the world. The reach of both traditional brands and newer branded entities has also broadened to include stakeholders who have not necessarily been consistently targeted in the past, such as employees, donors, partners, citizen-voters, activists, as well as local communities, governments, and society as a whole.

The role of brands has also broadened, with commercial brands increasingly expected to have a mission (or purpose) over and above shareholder value maximization. As societal norms change, companies are feeling the pressure to act in a sustainable manner or to take activist stances that may help society attain its goals or even support stakeholders who oppose such goals. Brand activism has led to new responsibilities for brand managers and chief executive officers, as well as the need to protect the large amount of customer data that companies collect in their efforts to manage brands.

\section{Mapping the Blurring and Broadening of Branding}

Figure 1 maps the blurring and broadening of branding. It illustrates - using four different types

of brands and the stakeholders that shape them — the potential dilution of brand ownership (depicted by dotted circles in the picture) and the broadening of branding entities, brand roles, and brand stakeholders. Figure 1 also illustrates that brand meaning is more dynamic in cases where brand ownership is more porous, and is cocreated by the brand with its stakeholders.

--- Insert Figure 1 here ---

Next, we examine the shifts in branding across four broad headings: (1) Rethinking the roles and functions of brands; (2) Rethinking brand value creation and co-creation; (3) Rethinking brand management; (4) Rethinking the boundaries of branding. As we highlight fundamental changes that are taking place, we also outline a future research agenda for each topic. As an example, Table 1 summarizes research topics that pertain to our first question relating to roles and functions of brands. 


\section{Rethinking the Roles and the Functions of Brands}

Researchers investigating brands have construed brands in many different ways, including as signals of quality (Erdem and Swait 1998; Wernerfelt 1988), knowledge structures held in an individual's memory (Janiszewski and Van Osselaer 2000; Keller 1993), instruments of identity expression and goal achievement (MacInnis and Folkes 2017), social actors and structures of both stasis and change (Muniz and O'Guinn 2001), and cultural icons (Holt 2002). As technology has vastly improved access to information, products, and people, these existing conceptions of brands need to be reassessed-that is, refocused, rethought, or abandoned altogether. We discuss future directions for this reassessment in the remainder of this subsection (see Table 1).

\section{Brands as Weak Quality Signals}

In the past, when consumers were faced with information asymmetry and imperfect information, brands served as quality signals that facilitated consumer choice. However, in a hyperconnected economy in which consumers can easily access information about brands using online channels, information asymmetry between brand owners and consumers has decreased, as search costs are lower (Lynch and Ariely 2000). Thus, a brand's quality signal could face interference from alternative signals of quality derived from the collective reviews and opinions available online.

Researchers need to understand the conditions under which consumers still trust firm communications about brands (vs. information intermediaries such as Yelp, TripAdvisor, and Rotten Tomatoes) and the impact of firm-generated versus marketplace-generated brand information on brand trust. How can firms manage a brand communication process that faces significant signal interference? How can brands shift the balance in their favor if the signals generated by the marketplace are mixed, reflecting a high level of consumer heterogeneity? What types of message content, form, and media placement have the best chance of reducing and counterbalancing potentially undesirable external 
brand signals?

\section{Brands as Mental Cues in Information-Rich Environments}

Brand information processing (how consumers acquire, use, and remember brand knowledge) depends on consumers' motivation, ability, and opportunity to process information (MacInnis, Moorman, and Jaworski 1991). Studies have proposed and tested multiple models of learning about brands, leveraging the notion that brands can act as cues that access knowledge held in consumers' memories (Janiszewski and Van Osselaer 2000). As consumers increasingly process information in a hyperconnected, attention-scarce environment, understanding of brand information processing may need to be augmented and extended (Yadav and Pavlou 2014). Existing dual-processing models (visual or verbal, heuristic or systematic, piece-by-piece or holistic; Sherman, Gawronski, and Trope 2014) assume that consumers can switch back and forth in real time from one channel to another and from one processing style to another. As consumers utilize multiple devices and channels in the context of hyperconnectivity, dual-processing models need to be further refined to examine how and when people switch from one processing style to another and how simultaneous processing of information from multiple devices or channels occurs over time (e.g., when consumers engage in multitasking).

Brand information processing models should also consider how sensory information contributes to brand awareness and choice. The impact of sensory information on processing of brand information has been previously investigated (e.g. Krishna 2010; Krishna and Schwarz 2014). For example, Saini and Lynch (2016) shows that familiar brands are preferred in online settings (relative to offline) when sensory information is diagnostic and plays a role in brand choice. But hyperconnectivity offers additional research opportunities in this area. Although many brands are experienced online in an arguably less sensorial environment, companies now have access to multisensory and highly interactive new technologies that appeal to multiple senses (sight, hearing, touch, taste, and smell) simultaneously. For instance, sensory rich retail environments, as well as augmented and virtual 
reality, allow people to experience the power of multisensory stimulation and consider brands in environments that may be dynamic and virtual. Online stores like Wayfair, Amazon and Target have launched mobile-augmented reality apps that allow consumers to shop for furniture by placing items in their own room settings (O'Shea 2019). In sensory-rich environments, the voluntary attention to brand stimuli and sensory cues may be more difficult to elicit and more likely to be replaced by involuntary attention or arousal to stimuli unrelated to the focal brand. Therefore, current models need to be revised to incorporate the paucity of consumers' voluntary attention and also account for the possibility that the role of sensory cues may change how brand information is processed.

\section{Brands as Instruments of Identity Expression}

Brands can be used to support a desired consumer identity, and be associated with humanlike traits (referred to as "brand personality") (MacInnis and Folkes 2017). The identity view of brands is based on the notion that brands become imbued with associations through their use. For example, consumers can use these brand associations in an instrumental way to construct and signal something about their own identity (Aaker, Benet-Martinez, and Garolera 2001), while employees can use corporate brands owned by their employer to convey professional status or to send a signal about their expertise (Tavassoli, Sorescu, and Chandy 2014). The identity view has more recently focused on the complex nature of identity, with brands being tied to multiple individual and group-based identities (Escalas and Bettman 2005; Swaminathan, Page, and Gürhan-Canli 2007), as well as being symbolic of culture (Torelli and Ahluwalia 2011). The consumer culture literature has also considered the instrumental role of brands as authenticating narratives for consumers" "identity projects" (e.g., Thompson, Rindfleisch, and Arsel 2006).

A consequence of hyperconnectivity is that consumers can now adopt multiple personae on their devices and change their identities frequently (Turkle 2017). As consumers increasingly spend time online, there is the potential for their online (or "virtual") self and their offline (or "true") self to 
diverge, possibly leading to identity conflict (Suh 2013). The multiple (sometimes conflicting) and dynamic identities of consumers, particularly across online and offline settings, require rethinking about how to leverage brands to build identities (Reed et al. 2012). Can brand associations be constructed and revised to allow for a more flexible view of identity, or would this create confusion from the perspective of the user or those who view such signals? Would consumers prefer that brands have a well-defined meaning that helps them anchor and retrieve one particular facet of their identity, with greater potential for sending stronger signals about a particular self, or would they be drawn more to malleable brands that accommodate a broader range of self-expression? A multidisciplinary approach that leverages both the consumer and society perspectives could examine the manner in which social groups can use brands in instrumental ways to achieve their social goals.

Finally, hyperconnectivity can facilitate access to a broader set of brands in the digital space that can be used by consumers to express their identity. This would afford consumers a richer set of identity building tools. At the same time, digital possessions have been shown to have lower selfrelevance (Bardhi and Eckhart 2017), which calls into question the strength of identification with brands in the digital space. Additional questions center around how consumers choose brands to identify with in this online, hyperconnected environment and the nature of relationships that consumers form with brands.

\section{Brands as Containers of Socially Constructed Meaning}

Researchers using a sociological lens have examined the role of brands as arbiters of social

trends, as catalysts for social interaction, and as societal symbols in the case of brands that attain iconic status (e.g., Holt 2002). Brands are expanding their social role, however, by increasingly becoming activist tools aligned with various social and political issues. Purpose-driven branding argues that brands should uphold societal values because doing so gives consumers an opportunity to use them in instrumental ways to show support for social causes. For example, Procter \& Gamble's recent Gillette 
and My Black is Beautiful campaigns took controversial positions with regard to gender and racial stereotypes, respectively (Jardine 2019).

It is tempting for brands that want to remain relevant, particularly in the eyes of millennial consumers, to take a stance on important social issues, but prescriptions on how to do so effectively are lacking. Yet, it is increasingly clear that "the future of brands is also inextricably tied to the future of society" (Clifton 2009, p. 246), and brands can act as vehicles for bringing about social change. As hyperconnectivity can amplify brands' social message, scholarly insights are necessary to understand the role of brands as purpose-driven entities and how firms can best align the social message of brands with the desired brand associations. The consumer and society perspectives could be utilized in exploring the implications of brand conversations and brand engagement for stronger social connections, as well as other determinants and consequences of this 'social brand engagement' (Kozinets 2014).

\section{Brands as Architects of Value in Networks}

Marketing scholars have extensively investigated brand partnerships and alliances from a dyadic perspective (Park, Jun, and Shocker 1996; Simonin and Ruth 1998). However, in a hyperconnected environment, brands are increasingly embedded in complex networks consisting of users, partners, cocreators, and co-owners. Prior research that has examined the performance impact of networks on value creation at the firm level (Swaminathan and Moorman 2009) can be extended to show how brands can extract value from their position in the network.

Leveraging network theoretic constructs to examine value creation in branded networks is a useful avenue for future research. Brands can provide value in networks in at least two ways. Due to advanced search and navigation capabilities, brands can simplify users' navigation through brandembedded networks, thus contributing to seamless user experiences on online platforms. Further, brands can create value by ensuring compatibility across branded entities in the network, in terms of 
both attributes and quality standards.

A case in point is Apple, a company that strives to make its products compatible with a broad range of complementary devices and ensures that all applications sold in the App Store meet its stringent quality standards. But not all brands can easily extend their networks: for instance, Google failed to successfully launch Google Health, a platform where consumers could consolidate their health information and interact with providers. As noted by Van Alstyne, Parker, and Choudary (2016), participants on both sides of the platform were not ready to engage at a level that would render the platform successful.

Additional research is necessary to identify strategies that brands can adopt to enhance the effective functioning of the brand ecosystem. The traditional conceptualization of user experience that relies primarily on product or service usage could be broadened to include interactions across an entire network or ecosystem that is linked to a specific brand. We term this "brand network user experience." A better understanding of the brand network user experience and how consumers derive utility from such a network is warranted. Finally, brands can not only help organize informational content on networks but also serve as gatekeepers of information (or products) they want consumers to see or purchase. The ongoing spread of "fake news" on social media platforms highlights the potentially critical (and controversial) role of branded platforms as entities that censor harmful content or products; how brands can achieve this role and perhaps derive value from it should be the focus of further research.

\section{Brands as Catalysts of Communities}

Researchers have examined brand communities and how they deliver value to their members (Muñiz and O'Guinn 2001), and affect the co-creation process. In this context, brands serve as catalysts of social interaction and community through shared consciousness and brand use, loyalty, and engagement among community members (Kaplan and Haenlein 2010). Hyperconnectivity has 
increased the potential for individuals to establish and join brand communities, be it newer types that are appearing on social networks or communities established by traditional brands online, such as the Sephora or Jeep brand communities, in which users post reviews and share information about brands and their new products.

New research on how brand communities emerge in a hyperconnected environment and what type of governance can make such potentially large communities successful is a worthwhile avenue for research. Branded communities can create value not only by enhancing the brand experience for users but also by providing firms with a forum to test out new ideas, collect feedback on brand actions, and better understand how brands are consumed. Brand communities may also offer social benefits, particularly in the context of growing social isolation and "aloneness" in society (e.g., Turkle 2017). Thus, it would be valuable to understand how brand communities can help combat loneliness despite the larger scale of social connections facilitated by hyperconnectivity.

\section{Brands as Arbiters of Controversy}

In addition to the role of brands as signals or nodes in memory, brands have been construed as symbols (Levy 1959). These symbols could be used in various forms of self-presentation to give meaning to consumers and their social position (e.g., Goffman 1959). While not denying their other functions, Levy (1959, p. 205) states that "things people buy are seen to have personal and social meanings" and that people use branded symbols to reinforce their view of self (both actual and ideal).

When brands are strong enough to serve as symbols, some also transition into roles of arbiters of controversy within the identity and sociopolitical realms. These brands often adopt controversial stances on key topics such as feminism, LGBTQ+ rights, and racial issues and, in doing so, appeal to consumers at the epicenter of cultural controversy. Nike's use of Colin Kaepernick's cause was widely debated but is now deemed as having galvanized thought on the issues of social justice and race in sports, particularly considering that such a large percentage of professional athletes are nonwhite. Nike 
was awarded the 2018 Marketer of the Year for the campaign by Advertising Age (Pasquarelli and Schultz 2018), and Nike's profits and stock valuations have climbed in the aftermath of this controversial stance. In this way, brands appear to have a stronger voice in a hyperconnected world, in which their messages on social and political issues can quickly spread and multiply. With a stronger voice comes the added responsibility of addressing important social issues in ways that can help society move forward.

Hyperconnectivity has not only afforded brands the opportunity to have a stronger voice but has also reduced their ability to stay "above the fray" on controversial topics. Absent a stance on such topics, consumers with deep brand connections may question the authenticity of the brand. Research has shown that perceived brand authenticity has four dimensions: continuity, credibility, integrity, and symbolism (Morhart et al. 2015). Integrity, which captures a brand's intentions and the values it communicates, along with symbolism, which reflects values that are meaningful to consumers, are particularly relevant in situations where brands face conflict. Failing to take a clear stance may lower perceptions of brand integrity and foster identity conflict among those consumers who use the brand in symbolic ways to communicate certain values. At the extreme, activist consumers can punish passive brands: for example, activist consumers and movements fueled by them such as \#GrabYourWallet have caused retailers to drop certain brands or companies to drop their top executives, as was the case with the \#DeleteUber movement, which contributed to the then-CEO of Uber - Travis Kalanick - to step down from the company (Bedat and Shank 2017). In this way, brands that try to avoid conflict can become the target of activist consumers who yield a louder megaphone in a hyperconnected environment.

Research in the context of brands as arbiters of controversy is only in its infancy. Many questions remain unanswered. For example, how does brands' participation in controversy (political or social) affect their customer base? How do message content and the emotional tone of messages in a 
controversy affect brand perceptions? How does brands' participation in controversial issues propagate on social media, and what is the role of the structure of their online social network (e.g., network centrality, network density) in the spread of brand information following a crisis incident? What new metrics (e.g., polarization, controversy score) can track the nature of conversation about brands in controversial settings?

\section{Brands as Stewards of Data Privacy}

As brand boundaries become blurred, data that brands can access about their customers have increased, shedding new light on what drives consumer attitudes and behavior. These data are a potential source of value for branded entities, which can use them to better target and customize their offerings to consumers. At the same time, increased access to customer data poses legal and ethical challenges, as consumers have grown more concerned about the confidentiality and security of their data (Steenkamp and Geyskens 2006). Brands that have misused customer data (or suffered from data breaches) have faced significant backlash and penalties from consumers and public policy officials.

Policy makers and consumers have begun emphasizing the important role of governmental regulations in moderating privacy concerns. Concomitantly, scholars have shown greater interest in understanding the implications of recent privacy regulations (e.g., General Data Protection Regulation in Europe) for both customers and firms (Goldfarb and Tucker 2011). As data themselves become a resource, understanding the implications of privacy concerns for brands and the trade-offs inherent in achieving greater personalization through data versus ensuring data privacy is a topic that needs greater research attention (Aguirre et al. 2016; Martin, Borah, and Palmatier 2017).

Even as regulations pertaining to data usage become more stringent, brands should take the lead in ensuring compliance with data standards both for themselves and to ensure transparency across all third parties that belong to their ecosystem. While taking such a stance would strengthen their value proposition, more research is needed on understanding how branded entities should enforce data 
standards throughout their ecosystem and the downstream consequences of such strategic actions on consumer response to brands. Theoretical insights from the firm and consumer perspectives can be leveraged to understand how brand associations change if the role of brands as stewards of data becomes more salient, and to what extent this role can strengthen the relationships between brands and their customers.

\section{Rethinking Brand Value Creation and Cocreation}

We alluded earlier to how hyperconnectivity has led to brands and their messages no longer being exclusively shaped by their owners. In this subsection, we elaborate on how firms can cocreate brands' experiences and meaning with their stakeholders, including customers, partners, and the public at large. We summarize pertinent future research questions in Table 2.

--- Insert Table 2 here ---

\section{Cocreating Brand Experiences}

Perhaps the most significant change in how brands deliver value in the digital economy is the cocreation of brand experiences with consumers or partners. So far, cocreation research has focused mostly on new product cocreation (Hoyer et al. 2010; Vargo and Lusch 2004), but recent work has begun examining the cocreation of brand experiences (Nysveen and Pedersen 2014).

Importantly, cocreation of the brand experience often occurs on digital platforms, defined as enterprises that "use the Internet to facilitate economically beneficial interactions between two or more independent groups of users" (Demary and Rusche 2018, p. 8). Examples of digital platform brands are Uber, Airbnb, LinkedIn, among others. Most digital platforms are branded, and their brand associations result from the interactions of multiple players who contribute to the creation and delivery of the brand experience. For example, property owners on Airbnb contribute to the success of the brand experience as much as the technology that enables this platform. Emerging research on 
platforms has focused primarily on the structure of such exchanges (Perren and Kozinets 2018) and how to monetize them (Landsman and Stremersch 2011) rather than on how the interactions between the firm and its stakeholders shape the brand.

Recent research highlights the unique drivers of engagement for platform brands (Eckhardt et al. 2019), but there are other important branding aspects of cocreation on digital platforms worthy of further research. For instance, how should firms design an optimal governance mechanism that will still allow them to maintain reasonable control over brand reputation and meaning? How can firms influence platform participants to reinforce the brand message and deliver a brand experience consistent with this message? What differential branding benefits (e.g., awareness, preference, resonance) accrue from the various types of platform designs (e.g., open vs. closed, centralized vs. decentralized)? Are branded platforms in the shared economy disrupting employment, and if so, what are the societal consequences of these disruptions and subsequent impact on the brand?

More generally, researchers should try to understand how much control firms should relinquish over the brand experience, while still maintaining the desired associations, and to what extent firms should formalize the cocreation process. Should all interested consumers be given an opportunity to cocreate, or should the firm work to identify segments of consumers who can yield better outcomes for the firm? By contrast, how should firms interact with the segment of passive, low-involvement consumers, and what are the consequences of cocreation by other consumers in this particular segment? Are certain brand types more malleable to cocreation efforts? What are the consequences (i.e., benefits and risks) of cocreated brand experiences on brand outcomes such as brand engagement?

For traditional brands that are incorporating digital platforms and channels into their strategy, there are interesting questions pertaining to the consumption experiences. For example, it is worth examining how brands effectively can effectively merge online and offline experiences. Theorizing the brand cocreation process from the firm perspective (how firms should manage and respond to 
cocreated brand experiences), the consumer perspective (how consumers cocreate and react to brand experience cocreation), and the society perspective (how cocreated brand experiences contribute to well-being and life satisfaction) could offer important insights.

\section{Cocreating Brand Meaning}

Companies not only cocreate brand experiences with their customers, but some are even offering consumers the opportunity to design brand advertisements (Steenkamp 2017). While research has begun examining the cocreation of brand meaning through outsourced advertising campaigns (Thompson and Malaviya 2013), extensions of this work should address various facets and consequences of outsourcing the design of brand communications to consumers (Wang et al. 2019)

Even if firms wish to maintain full control over how they design and promote brand meaning, the rise of social media has led to weakened firm control over the brand meaning in the marketplace (Herhausen et al. 2019). Many-to-many communications on ubiquitous social media platforms have ushered in an era in which dynamic and real-time conversations are taking place among consumers on a massive scale (Berger and Milkman 2012; Tellis et al. 2019). This has created a large volume of user-generated content that has made it easier for marketers to "listen" to consumers on social media platforms. Such listening has allowed marketers to derive unique insights into customer needs and wants, thus allowing them to replace costly traditional marketing research with low-cost, granular data available through social listening via user-generated content (Netzer et al. 2012). At the same time, research has highlighted the amplification of positive and negative information in social media and its effects on brands (Hewett et al. 2016).

Understanding the implications of consumer-generated content on downstream outcomes, such as customer engagement, and the motivations for consumers to engage in generating word-of-mouth communications are two broad areas that have garnered research attention (Barasch and Berger 2014; Lovett, Peres, and Shachar 2013; Meire et al. 2019). Further research should build on these findings to 
determine the optimal balance of firm- versus user-generated content that can enhance consumers' perceptions of brand authenticity and increase their willingness to engage with a brand. All three theoretical perspectives can be leveraged to understand how consumers respond when brand meaning is cocreated by others. Finally, additional research is necessary on which online platforms or media can shape and significantly influence the meanings associated with particular brands, along with the best methods and metrics that can mine the data collected from these sources.

\section{Creating New Brands in a Hyperconnected World}

Extant research on the determinants of new brands' performance has focused mainly on the consumer packaged goods industry and on marketing-mix and firm-strategic actions, such as discounting, feature/display, advertising, or distribution, with the breadth of the latter playing the greater role in the success of a new brand (Ataman, Mela, and Van Heerde 2008). Going beyond packaged goods categories, further research should focus on branding aspects in emergent categories of new goods and services. The breadth of new offerings, ranging from digital platform brands (e.g., TaskRabbit), to smart products (e.g., artificial intelligence toothbrushes such as Ara by Colibree), to new business models powered by new technologies (retail stores without a cashier such as Amazon Go), requires a fresh perspective on how to brand and manage complex products that interact in newer ways with their owners and with complementary products than more traditional products.

What are the key success factors of such new branded products? Owing to disintermediation (involving switching or elimination of traditional intermediaries in distribution channels) and reintermediation (addition of new forms of intermediaries in distribution channels), we expect traditional channels of distribution, and related factors examined in prior research, to be less important in the future (Gielens and Steenkamp 2019). Rather, success will likely depend on the degree to which a brand can leverage hyperconnectivity among networks of people and devices. One manifestation of the easy access to consumers is the proliferation of direct-to-consumer brands such as Bonobos (men's 
clothing), Harry's (shaving), Glossier (cosmetics), and Warby Parker (eyewear). But direct-toconsumer brands do not only leverage hyperconnectivity by selling their products online; rather, they seek to provide a distinct brand experience that sets them apart from their brick-and-mortar competitors by tapping into their network of consumers. Maras (2018) describes how Glossier sought to make the customers an integral part of the buying experience. Glossier invites its customers to share product ideas, and incentivizes them to share their Glossier brand experiences with their followers across social media channels such as Instagram. In this way, Glossier's network of customers are evangelists for the brand.

Three facets of hyperconnectivity are particularly relevant in the context of new brands: networked communications, network value creation, and data collection. In terms of networked communications, information and positive word of mouth about innovative new products can spread fast via global social media and buying platforms, thus securing early adopters faster than ever before (Nguyen and Chaudhuri 2019). Network value creation in a hyperconnected world will require smart products that connect with other products and provide value as a network or system; that is, they need to be "connectable" and connected with other brands (Novak and Hoffman 2019). Brands have formed partnerships and alliances for decades to create add-on value; in the future, connecting with other brands will be at the very core of a brand's value creation and will precipitate the growth of a variety of related applications, such as augmented reality, blockchain, wearable technology, chatbots, and gamification (Simões, Filipe, and Barbosa 2019). Finally, new brands are more likely to be perceived as innovative and valuable for the firm, consumers, and society if they collect data and make those data, or the features built on them, available to relevant stakeholders. For example, streaming services (e.g., Netflix, Hulu) leverage data gathered from consumers to recommend new shows to their audiences. Scholars should investigate ways in which data can be leveraged to be a central aspect of the value creation of a new brand. For instance, the brand Proven was created by applying artificial 
intelligence algorithms to vast quantities of data pertaining to ingredients, customer reviews and scientific journals with the goal of identifying the most effective ingredients and creating a customized, data-driven line of skin care (Taylor 2018). In doing so, data can not only help improve firms' operations but also, if done responsibly, be of benefit to society.

If the ability to connect to other brands is key to a new brand's success, how should the brand be built? Product designs of the brands of the future will need to include sensors and receptors to leverage the device-to-device connectivity as discussed previously (Novak and Hoffman 2019). Researchers need to determine conditions under which it is more effective for brands to establish their own ecosystem, as Apple has done, or plug into another one that allows them access to consumers and other brands. Moreover, brands of the future - whether smart home appliances, office equipment, cars, or industrial products—-will not be fixed and static; they will be updated constantly, some even in real time, because their core design will also include software, not just hardware. As noted by Schmitt (2019), the digital revolution has moved the focus of brands "from atoms to bits" (that is, from tangibles to intangibles), but the next wave of this revolution may involve incorporating smart technologies such as artificial intelligence, blockchain, and augmented and virtual reality into brands. Some of these technologies require deeper access to consumers' lives that may be perceived as intrusive. To what extent consumers are willing make a tradeoff between privacy concerns and the ability to have their products updated and maintained in real time is an interesting area of research inquiry.

Finally, new brands will not be about ownership. The ownership model will likely be complemented by access- and occasion-based liquid consumption (Bardhi and Eckhardt 2017; Eckhardt et al. 2019). The very notion of brand, as a clearly defined entity that needs to create awareness and image among stakeholders to induce loyalty among them, may even become obsolete and be replaced by a more transient model of value creation among interconnected devices that do not 
require much labeling and branding. If the importance of brands will diminish, what mechanism can replace brand equity to induce loyalty and trust in consumers? What factors will determine product choice in this new world? The new reality of branding described in this section calls for significant changes in the management of brands, which we examine next.

\section{Rethinking Brand Management}

In this subsection, we discuss several key aspects of brand management that have been affected by hyperconnectivity. Table 3 presents pertinent future research questions in this domain.

\section{--- Insert Table 3 here ---}

\section{Blurred Control of Brand Positioning and Brand Communication}

Before the advent of the Internet, firms chose the positioning of their brands and sought to achieve it through carefully controlled and designed communications. Hyperconnectivity has

fundamentally changed the way firms both position their brands and talk about them. Firms now must contend with three major changes. First, their competition has significantly broadened as connectivity has heightened consumer access to a large set of brands. Second, the Internet and mobile devices offer a much broader space and more ways to communicate brand messages, making it more difficult to optimize message placement (Goldfarb and Tucker 2011). Second, as we alluded to previously, firms' brand communications are supplemented and may even be dwarfed by those generated from outsiders (e.g., Tellis et al. 2019). Thus, firms' brand messages may not only be blurred but also substantively modified by brand opinions generated by outsiders.

In terms of positioning, branding's pervasiveness across products, people, places and ideas makes it more difficult for firms to clearly delineate their competitive space and to find a unique message that cuts across digital clutter. At the same time, just as consumers have access to numerous brands in the digital space, firms' potential consumer base is also increasing, raising important 
questions about how firms should handle consumer heterogeneity and to what extent they should modify their message and offering to cater to such heterogeneity. Prior research has shown that differentiation is a double-edged sword, as it is associated with higher customer profitability, but also associated with lower acquisition and retention rates (e.g., Stahl et al. 2012). More research is needed on strategies that can allow companies to wield this sword more effectively. This is of particular relevance in a hyperconnected context where consumers may find it impossible to engage deeply with the multitude of brands that they encounter in their lives.

In terms of the design and placement of brand messages, firms face an almost infinite number of advertising formats and channels. However, the effectiveness of these ads is being questioned, as firm communications in general and brand messages in particular are fighting information overload. Many firms are coping with the complex task of ad placement by relinquishing some control to algorithms that help with ad placement. This also has potential downsides, as ads may be placed alongside content that is deemed unsafe or controversial. Research on the consequences of brand advertising online and on mobile apps is emerging (e.g., Du, Xu, and Wilbur 2019; Wang, Xiong, and Yang 2019), but it is far from being able to provide clear prescriptive implications about the consequences of advertising for brand safety in a given digital space. How do consumers react if a brand inadvertently advertises on a webpage that is associated with content (such as hate speech) consumers may find offensive? What are some effective approaches to ensuring transparency throughout the advertising and media supply chain so that brands can evaluate and enforce safety of their advertised content? More research is needed to examine these questions in greater detail.

We highlighted the cocreation of brand meaning as one of the main consequences of hyperconnectivity. Firms are still searching for optimal ways to monitor, gather, analyze, and respond to brand information generated online. Many firms are investing in social media-listening control rooms or in engagement platforms that can help them better manage brands on an ongoing basis 
(Ramaswamy and Ozcan 2016). From a capability standpoint, future research should offer stronger insight into how data scientists (responsible for gleaning insights from social media listening) can work with brand strategists within a firm to design optimal communications that leverages the insights from a continually evolving in online conversation spaces.

From a brand management standpoint, firms need a consistent approach for identifying which consumers have more influential voices, what metrics best capture this influence, and what is the best response (in terms of message and medium) to shifting brand associations driven by outside stakeholders. This topic has recently received greater attention in scholarly research (e.g., Herhausen et al. 2019), and it is generating more interest in what firms can do to manage the conversation. As brand dialogues evolve in online conversation spaces, the effectiveness of firms' engagement in these dialogues will determine the extent to which they can control, at least in part, the brand message.

Scholarly insights into how firms can optimally design metrics dashboards are also necessary to ensure that firms can quickly disseminate relevant insights gleaned from big data. Finally, research needs to develop theory-rooted risk mitigating strategies that will allow brand managers to identify and correct deviations from the main brand message when these become prevalent in online conversations.

\section{Blurred Control of Brand Crises}

The more porous ownership of brands carries with it the risk of crises arising from the actions of platform partners. Digital platform brands as well as traditional branded entities operating in a hyperconnected world must design and implement governance and response mechanisms that can minimize the loss of brand equity, when even trusted stakeholders such as firm partners and employees can take actions that hurt the brand. Branding researchers should therefore conceptualize and empirically test the effectiveness of governance mechanisms that safeguard against stakeholders' nefarious actions. Building on prior research findings (Dawar and Pillutla 2000), research should evaluate the impact of various types of brand crises (precipitated by different stakeholder groups) on 
how consumers' attribute blame across platform partners.

Hyperconnectivity does not stop at country borders (Dinner, Kushwaha, and Steenkamp 2019). Consequently, novel metrics for tracking both short- and long-term impacts of brand crises on both a local and an international basis, and across both financial (e.g., stock market reaction) and nonfinancial (e.g., brand trustworthiness, engagement) factors represents a fruitful area of research inquiry. Identifying the structures of brand teams that will facilitate optimal responses to brand crises will also be an important area for further research. Finally, understanding the implications of brand crises for employee engagement and satisfaction is also a key research issue.

\section{Blurred Control of Brands as Identifiers of Intelligent, Interactive, and Networked Devices}

Radical new technologies have transformed brands from mere consumption objects to intelligent, interactive devices. As the next wave of the digital revolution is taking shape, the Internet of Things will allow branded devices to interact and exchange information with each other (Hoffman and Novak 2017; Ng and Wakenshaw 2017). Brands are mostly trademarked goods; in the context of hyperconnectivity, it is even more important to monitor how they are presented and identified across a broad range of devices, settings and channels. Some of these settings could be outside the control of brand managers, raising questions about the best way to manage the operations and promotion of brands that operate as part of networks of products.

The rise of artificial reality - the creation of an interactive experience of a real-world environment through computer-generated displays — and virtual reality — a complete simulation of the environment — also has a bearing on brands and their boundaries. Researchers need to understand how these technologies, which are able to seamlessly blend the real and virtual worlds, can create unique brand experiences for consumers before, during, and after purchase. Entertainment brands including video games such as Pokémon Go, or museums such as the Metropolitan Museum of Art, have combined aspects of real and virtual worlds to maximize the user experience across online and offline 
channels. The advent of artificial intelligence and its physical substrate (robots ranging from chatbots to full-fledged humanoids) raises questions of how to brand nontangible information and nonhuman, but humanlike, autonomous agents and how to use artificial intelligence as part of brand decision making and service delivery.

\section{Measuring Brand Value}

Traditional brand valuation methods revolve around consumer-based brand equity, often measured with survey instruments such as the Brand Asset Valuator, the revenue premium that accrues to the brand, and brand discounted cash flows (Datta, Ailawadi, and Van Heerde 2017). These methods need to be updated to reflect the role of brands in a hyperconnected world. For example, as brands are increasingly deriving their appeal from cultural meanings, some pillars of brand equity (e.g., meaningfulness) may become more important than others (e.g., salience) (Fournier and Alvarez 2019). A revenue premium-based approach to assessing brand equity can still help assess short-term brand value but might not adequately capture the extent to which some brands may be better connected with their customers than with other stakeholders.

However, more exciting research challenges may be found in valuing brands that are born in and directly leverage hyperconnectivity —in particular, platform brands. How to value these brands, which typically have limited assets and sometimes little income, is both a managerially and academically important question. Practitioners' evaluation of platform brands varies significantly. For example, in 2018 Facebook had a brand value of $\$ 162.1$ billion according to BrandZ versus only $\$ 45.2$ billion according to Interbrand. For Netflix, the numbers were $\$ 20.8$ billion and $\$ 8.1$ billion, and for Spotify $\$ 15.7$ billion and $\$ 5.2$ billion, respectively.

One approach to measuring the value of these types of brands would be to use the standard financial approach: brand value $=$ current profit/(interest rate - profit growth rate). However, this standard approach may not be valid for networks, particularly if the network does not yet have any 
profits or if the profit growth rate exceeds the interest rate. Another approach suitable for subscriptionbased businesses is to calculate the customer lifetime value for each network member from his or her own discounted cash flows (Gneiser et al. 2012). This alternative is based on customer equity theory (Rust, Lemon, and Zeithaml 2004) but may not be particularly robust in a world in which people can easily cancel or change subscriptions.

Recent approaches to brand valuation in the context of networks take the user base into account, assuming that networks are more valuable if the social capital of its members is higher (Adler and Kwon 2002). Bourdieu (1986, p. 248) defines social capital as "the sum of total resources, actual or virtual, that accrue to an individual (or group) by the virtue of being enmeshed in a durable network of more or less institutionalized relationships of mutual acquaintance and recognition." Thus, the value of a brand that operates on a network increases as a function of current profit and size of the user base, but also with the social capital and social structure of its user base. However, consensus is lacking on the functional form of this relationship (Zhou and Van Alstyne 2019) and, in particular, on how to incorporate the intangible value that resides in the relationships between users into the value of the platform brand. Further research is necessary to understand whether social capital should be measured at the individual level and then aggregated to the network or directly at the network level, to capture unobserved synergies in social capital. In addition, the role of the quality of social capital needs further examination. Bourdieu's "relationships of mutual acquaintance and recognition" may be weak in networks such as LinkedIn in which connections may be distant and nonconsequential. A more contemporary view on social capital seems essential to future research (e.g. Field 2017), and acknowledges branding to be of societal importance beyond the goals of the individual marketer (Putnam 2001).

Another important component of the valuation of brands on networks is the structure of the network. What kind of structure is more valuable? Is a tight-knit, cohesive structure (niche strategy) 
with many redundant ties more valuable (Coleman 1988) or a sparse network with few redundant ties (undifferentiated market saturation strategy), which facilitates wider diffusion of information (Burt 1992)? Finally, researchers focused on this type of valuation will need to determine the relative importance of the various inputs (current profit, user base, social capital, and network structure) and assess whether their weights may differ by industry and type of network. Measuring brand value of idea and person brands also poses unique challenges that marketers need to address.

\section{Rethinking the Boundaries of Branding}

In recent years, branding research has broadened its scope to include brands from emerging countries (Melnyk, Klein, and Völckner 2012), branding in a digital environment (e.g., Tellis et al. 2019), and the branding of new entities such as place, organization, idea, and person (e.g., Fournier and Eckhardt 2019; Steenkamp 2020). We chose to focus primarily on three types of noncommercial, nonmarketplace entities_-ideas, persons, places—because these entities have leveraged hyperconnectivity in unique ways to attract large numbers of followers, but we also briefly refer to branded organizations. Table 3 presents illustrative future research questions that can advance knowledge on newer branded entities.

--- Insert Table 3 here ---

\section{Idea Brands}

We evaluate idea brands as an example of a newer branded entity, though ideas have had a long history of being branded. For example, ideologies such as Puritanism, Calvinism, Communism, and Neo-Liberalism have also leveraged branding to gain adherents and to articulate their principles in a consistent manner. The American Dream, New Deal, Reaganomics, and The Green New Deal are examples of branded initiatives originating from political entities and parties who make concerted efforts to obtain support, gain followers, build emotional relationships, and raise funds. We define idea 
brands as ideologies, initiatives, or other abstract, noncommercial notions that are identified by their stakeholders and the public at large using the same specific name. In other words, a set of ideas becomes branded when its stakeholders and the public at large use a specific label to refer to it, to affiliate with it, or to promote it. Idea brands span many domains-social, political, cause-related, and religious - and can evolve across domains; for example, cause-related ideas can morph into social causes as their popularity and supporter base increase (Fine 1981). They are relatively ephemeral and highly dynamic entities, susceptible to hijacking, change, or even elimination. The dynamic nature of idea brands is further exacerbated by hyperconnectivity, as online social networks and platforms can sanction and spread them, reshape them, or oppose resistance to them.

In light of these important differences, additional systematic research is required on how, when, and why certain idea brands are more successful than others. The hyperconnected era has increased the speed and scale at which ideas are disseminated, creating an urgent need for new models of how ideas diffuse and when and how ideas morph into social movements. Researchers could combine insights from research on diffusion and contagion theory (Centola 2018) with elements from sociological theories related to social movements, to elucidate the spread of different types of ideas (e.g., political, religious, social). An in-depth examination of the distinct ways that good ideas spread (e.g., humanitarian causes) relative to bad ideas (e.g., terrorism, racial intolerance) is also necessary. Furthermore, the consumer and society perspectives could come together to elucidate the differences between more and less authentic ideas, to identify the characteristics of groups they appeal to, and to evaluate their impact on the social actions of the individuals who adopt or oppose them.

\section{Person Brands}

A second type of branded entity that is gaining prominence in the context of hyperconnectivity is a person brand. Research has referred to a brand that it also a real person as a person brand (Fournier and Eckhardt 2019), human brand (Thomson 2006), or celebrity brand (Kerrigan et al. 2011). These 
types of brands have been used by everyone from a publicly visible and public-relations-conscious celebrity or politician to any person who uses a platform or engages in a form of self-promotion that is visible to his or her constituency. For example, Banet-Weiser (2012) shows how teenage girls create and try-out their many personal brands online, and how marketers, in turn, scrape the web for these incredibly rich data that before the hyperconnected world would have been too expensive, lacking ecological validity, and highly restricted and regulated by law and practice. The ability to create and promote a person brand online has led to the rise of influencers, a category of individuals who appear to have high potential as brand promoters, and whose impact on brands and their meaning is the focus of recent scholarly research (Hughes, Swaminathan, and Brooks 2019).

In analyzing the distinct characteristics of person brands, Fournier and Eckhardt (2019) stress the challenges involved in unifying person and brand, as they are inextricably linked, mutually interdependent, but not identical. They argue the key characteristics that define a person (mortality, hubris, unpredictability, and social embeddedness) can upset this mutually interdependent relationship and cause inconsistency and imbalance. In highlighting this aspect, Fournier and Eckhardt (2019) argue that this distinctive aspect of person brands (i.e., integrating across the person and the brand) creates unique risks for their management.

More research is needed to identify how these risks occur and can be mitigated. The downstream consequences (monetary and nonmonetary) of reputational losses associated with crises and scandals involving person brands are also worth examining, as hyperconnectivity can magnify the scale and scope of such losses, particularly in the short run. By contrast, the consequences of reputational losses may diminish over long-term windows from the volume of information and velocity with which information is continually updated. Building on the notion of interdependencies between person and brand, research could also investigate how this delicate balance shifts in the aftermath of a reputational crisis and whether a greater shift in focus on the shortcomings of the "person" actually 
improves overall perceptions of authenticity associated with the person brand.

As more people begin to adopt branding principles to promote themselves, understanding the societal implications of such actions is important. On the one hand, adoption of person branding principles by noncelebrities could strengthen the ability of these individuals to become more attractive employees or more attractive dating partners. On the other hand, an excessive focus on self-promotion may also have a variety of negative consequences. For example, McCain and Campbell (2018) highlight the unhealthy self-obsession and growth of narcissism as one potential consequence of leveraging social media to build one's brand. Understanding these effects of person branding on narcissism and its consequent implications for feelings of belongingness, happiness, and well-being are research issues that merit further investigation.

Furthermore, research should investigate the differences between brands built by average people and celebrity brands and identify the optimal approaches for reputation building across these two types of person brands. Another useful approach would be to distinguish between economic (“commercial”) and noneconomic ("noncommercial”) person brands. Commercial person brands such as celebrities, (micro) bloggers, and digital opinion leaders have their own following, and they derive income from sponsorships and sales recommendations and by branding their product lines (e.g., Kylie Jenner's Kylie Cosmetics). Much of the value of these person brands resides in their network, and future research should try to evaluate novel brand valuation approaches for this context.

\section{Place Brands}

A place brand can be defined as "a network of associations in the consumers" mind based on the visual, verbal, and behavioral expression of a place, which is embodied through the aims, communication, values, and the general culture of the place's stakeholders and the overall place design" (Zenker and Braun 2010, p. 5). Place branding is more than merely measuring the perceptions of the individuals who interact with that locale: place can be a sociological construction or an actively 
managed image-building and management strategy (Kotler and Gertner 2002). Place brands develop as a result of complex interactions among residents, influenced by culture, history, and are thereby seen as dynamic, socially constructed, culturally dependent, and communally owned entities (Ballantyne and Aitken 2007).

Like idea brands, the ownership of place brands is spread over multiple stakeholders (such as city governments, residents, tourists). These stakeholders could potentially have conflicting objectives, as exemplified by the opposing goals of tourists and residents in cities such as Amsterdam and Berlin (Cancian 2019). The differential role of multiple stakeholders in the development of place brands would be worth investigating, drawing on multiple disciplines such as political science, sociology, anthropology, cross-cultural psychology, urban planning, geography, and tourism research. Insights from the consumer and society perspectives could be integrated to conceptualize and measure place branding outcomes across various stakeholders, as well as to better understand intangible outcomes (Potapov, Shafranskaya, and Bozhya-Volya 2016), such as life satisfaction of citizens and overall societal well-being. Spaces smaller than a city but commercially vital, such as Times Square, or trendy-shopping spaces such as Ginza (Tokyo) could also be researched in this day of the decline of the shopping mall. Factors such as the social density, social class perceptions and the implications for place brands should be examined (O'Guinn, Tanner, and Maeng 2015), particularly in the context of a hyperconnected world.

Place branding research has so far focused on how place brands are created and consumed, and how place brand identity develops (Lucarelli and Berg 2011). Place attachment has examined how people forms associations with a place based on their childhood experiences (Morgan 2009). More recent research (Thomas and O'Guinn 2019) draws on the large urban sociology literature to understand how branded spaces work through community, moral codes, and symbolic boundaries. Place brands share commonalities with other types of branded entities (for instance, their meanings are 
cocreated as are those for idea and platform brands) but also differ in important ways: Brand communications have to account for the diverse and potentially heightened social sensitivities that result from these conflicts.

\section{Organizations as Brands}

A fourth type of branded entity that is worth closer scrutiny in the era of hyperconnectivity is organizations. Research has investigated organizations mostly in their corporate form and corporate brands mostly along the notions of corporate identity and corporate reputation (Abratt and Kleyn 2012; Ind 1997). But there is much more to organizations as brands. They have responsibilities to communities, to the environment, and, of course, to their own employees. The best manner in which organizations can create and deliver a purpose within society that aligns well with their brand associations and mission is an area that still requires research. Also, more nefarious organizations (e.g., terrorist organizations) that aim to overthrow the existing order through violence keenly understand the power of branding as well (Beifuss and Bellini 2013). Developing a deeper understanding of what drives brand perceptions for organizations that serve the common good and what could disrupt the branding efforts of infamous organizations might be a worthy research endeavor.

\section{Metrics for Newer Branded Entities}

We earlier discussed challenges and opportunities associated with measuring brand value in a hyperconnected environment. Newer branded entities such as noncommercial idea and person brands are uniquely difficult to value because generating cash flow may not be their purpose. Rather, their relevant metrics may be influence, power, votes, societal well-being (e.g., social justice, fighting climate change), or converts. Might consumer-based brand equity be a useful point of departure for valuing such brands? If so, what would be the relevant dimensions? Are traditional consumer-based brand equity measures such as those in the Brand Asset Valuator (Datta, Ailawadi, and Van Heerde 2017) relevant or sufficient? What would a properly conceived of consumer-based brand equity 
measure for noncommercial idea and person brands indicate about the actual strength of the brand? To answer these questions, researchers need to link this measure to the relevant outcome metrics for such brands. Another factor to consider when developing new methods to value idea and person brands is the greater risk associated with inconsistency and potential threats of scandals or crises (Fournier and Eckhardt 2019). This may require a different approach to risk management than what has been used for traditional brands.

\section{Conclusion}

This article focuses on future contributions to brand research, management, and measurement in a hyperconnected world in which the boundaries of branding have been blurred and broadened.

In light of both broadening and blurring of brand boundaries, we address three key questions that form the focus of our inquiry: (1) What are the roles and functions of brands? (2) How is brand value (co)created? and (3) How should brands be managed?

We take a dual perspective in this article. On the one hand, we describe how hyperconnectivity has led to several new roles for brands. On the other hand, we re-examine how some traditional roles of brands (e.g., brands as signals of quality or as mental cues), have changed in a hyperconnected environment. We do so using firm, consumer and society theoretical perspectives. We describe how hyperconnectivity contributes to several new roles in which brands are containers of socially

constructed meaning, architects of value in networks, catalysts of communities, arbiters of controversy, stewards of data privacy among others. Many of these new roles can be the focus of research from multiple disciplinary perspectives, and we highlight a variety of research questions that can draw from different theoretical perspectives throughout the paper. As brand boundaries are blurring, we also discuss the shift towards cocreated brand meanings and experiences, enacted via digital platforms which facilitate such cocreation. 
Given the complex nature of brands today and in the future, we hope researchers will engage in future boundary-breaking research on topics like those outlined in our paper. As our review attests, one implication of hyperconnectivity for branding research lies in the fact that brands will need to be conceptualized more broadly within each of the theoretical perspectives in the extant brand literature. The consumer and the firm perspectives should focus more on consumers and firms as part of networks, rather than on their roles as individual buyers or managers of brands. The society perspective should go beyond the role of brands as cultural symbols and examine them as agents of social change. Moreover, we propose that brands are more than symbols attached to products that are owned by individual firms. They can be ideas, persons, and places.

There is also an opportunity to examine topics that cut across these theoretical perspectives. For example, the firm perspective will need to embrace societal questions as organizations or corporate brands will be asked to address broader issues including social responsibility, sustainability, and human-resource practices that go beyond profit maximization. Instead, brands need to fulfill a broader mission and purpose. The consumer perspective will also have to be more rooted in the society perspective as consumers form networks that are becoming distinct and occasionally vociferous entities that can shape both managerial practice and societal trends. The impact of network on brands, like that of communities, requires additional sociological, psychological, and cultural insight. Given our experience, we believe that such work would benefit from increased collaboration among branding researchers of different backgrounds, including teams of marketing strategists, economists, modelers, psychologists, sociologists, and consumer culture researchers. 


\section{References}

Aaker, David A. (1996), Building Strong Brands. New York: The Free Press.

Aaker, Jennifer L., Veronica Benet-Martinez, and Jordi Garolera (2001), "Consumption Symbols as Carriers of Culture: A Study of Japanese and Spanish Brand Personality Constructs," Journal of Personality and Social Psychology, 81 (3), 492-508.

Abratt, Russell and Nicola Kleyn (2012), "Corporate Identity, Corporate Branding and Corporate Reputations: Reconciliation and Integration," European Journal of Marketing, 46 (7/8), 1048-63.

Adler, Paul S. and Seok-Woo Kwon (2002), "Social Capital: Prospects for a New Concept," Academy of Management Review, 27 (1), 17-40.

Aguirre, Elizabeth, Anne L. Roggeveen, Dhruv Grewal, and Martin Wetzels (2016), "The PersonalizationPrivacy Paradox: Implications for New Media," Journal of Consumer Marketing, 33 (2), 98-110.

Ataman, M. Berk, Carl F. Mela, and Harald J. Van Heerde (2008), "Building Brands," Marketing Science, 27 (6), 1036-1054.

Bahadir, S. Cem, Sundar G. Bharadwaj, and Rajendra K. Srivastava (2008), "Financial Value of Brands in Mergers and Acquisitions: Is Value in the Eye of the Beholder?" Journal of Marketing, 72 (6), 49-64.

Ballantyne, David and Robert Aitken (2007), "Branding in B2B markets: Insights from the Service-Dominant Logic of Marketing," Journal of Business \& Industrial Marketing, 22 (6), 363-71.

Banet-Weiser, Sarah (2012), Authenticтм: The Politics of Ambivalence in a Brand Culture. New York: New York University Press.

Barasch, Alixandra and Jonah Berger (2014), "Broadcasting and Narrowcasting: How Audience Size Affects What People Share," Journal of Marketing Research, 51 (3), 286-99.

Bardhi, Fleura and Giana M. Eckhardt (2017), "Liquid Consumption," Journal of Consumer Research, 44 (3), 582-97.

Batra, Rajeev, Aaron Ahuvia, and Richard P. Bagozzi (2012), "Brand Love," Journal of Marketing 76 (2), 1-16.

Bedat, Maxine and Michael Shank (2017), "Every Purchase you Make Is a Chance to Vote with Your Wallet," Fast Company, https://www.fastcompany.com/40402079/every-purchase-you-make-is-a-chance-to-votewith-your-wallet, accessed on 12/18/2019.

Beifuss, Arthur and Francesco Trivini Bellini (2013), Branding Terror: The Logotypes and Iconography of Insurgent Groups and Terrorist Organizations. London: Merrell Publishers.

Berger, Jonah and Katherine L. Milkman (2012), "What Makes Online Content Viral?” Journal of Marketing Research, 49 (2), 192-205.

Bharadwaj, Sundar G., Kapil R. Tuli, and Andre Bonfrer (2011), "The Impact of Brand Quality on Shareholder Wealth," Journal of Marketing, 75 (5), 88-104.

Black, Iain and Cleopatra Veloutsou (2017), "Working Consumers: Co-Creation of Brand Identity, Consumer Identity and Brand Community Identity," Journal of Business Research, 70, 416-29.

Bourdieu, Pierre (1986), "The Forms of Capital," in Handbook of Theory and Research for the Sociology of Education, J. Richardson, ed. Westport, CT: Greenwood, 241-58.

Brakus Josko, Bernd Schmitt, and Lia Zarantonello (2009), "Brand Experience: What Is It? How Is Measured? Does It Affect Loyalty?" Journal of Marketing, 73 (3), 52-68.

Broniarczyk, Susan M., and Jill G. Griffin (2014) "Decision Difficulty in the Age of Consumer Empowerment," Journal of Consumer Psychology 24 (4), 608-625.

Burt, Ronald (1992), Structural Holes: The Social Structure of Competition. Cambridge, MA: Harvard University Press.

Cao, Zixia and Alina Sorescu (2013), "Wedded Bliss or Tainted Love? Stock Market Reactions to the Introduction of Cobranded Products," Marketing Science, 32 (6), 939-59.

Cancian, Dan (2019), "Dutch Towns Are Being Overrun With Tourists and the Locals are Fighting Back," Newsweek, https://www.newsweek.com/netherlands-tourism-amsterdam-crowds-control-1417479, accessed on $12 / 18 / 2019$.

Cayla, Julien and Giana M. Eckhardt (2008), "Asian Brands and the Shaping of a Transnational Imagined Community," Journal of Consumer Research, 35 (2), 216-30. 
Centola, Damon (2018), How Behavior Spreads: The Science of Complex Contagions. Princeton, NJ: Princeton University Press.

Chevalier, Judith A. and Dina Mayzlin (2006), "The Effect of Word of Mouth on Sales: Online Book Reviews," Journal of Marketing Research, 43 (3), 345-54.

Clifton, Rita (2009), "The Future of Brands," in Brands and Branding, Rita Clifton, ed. New York: Bloomberg Press, 246-60.

Coleman, James S (1988), "Social Capital in the Creation of Human Capital," American Journal of Sociology, 94, S95-S120.

Datta, Hannes, Kusum L. Ailawadi, and Harald J. van Heerde (2017), "How Well Does Consumer-Based Brand Equity Align with Sales-Based Brand Equity and Marketing-Mix Response?” Journal of Marketing, 81 (3), $1-20$.

Dawar, Niraj and Madan M. Pillutla (2000), "Impact of Product-Harm Crises on Brand Equity: The Moderating Role of Consumer Expectations," Journal of Marketing Research, 37 (2), 215-26.

Demary, Vera and Christian Rusche (2018), "The Economics of Platforms," Research Report IW-Analysen 123, https://www.econstor.eu/bitstream/10419/182531/1/1031227806.pdf, accessed on 12/18/2019.

Dinner, Isaac, Tarun Kushwaha, and Jan-Benedict E.M. Steenkamp (2019), "Marketing Capabilities and International Marketing Crises: The Role of Psychic Distance," Journal of International Business Studies, 50 (April), 339-64.

Du, Rex Yuxing, Linli Xu, and Kenneth C. Wilbur (2019), "Immediate Responses of Online Brand Search and Price Search to TV Ads," Journal of Marketing, 83 (4), 81-100.

Eckhardt, Giana M., Mark B. Houston, Baojun Jiang, Cait Lamberton, Aric Rindfleisch, and Georgios Zervas (2019), "Marketing in the Sharing Economy," Journal of Marketing, 83 (5), 5-27.

Epp, Amber M., Hope Jensen Schau, and Linda L. Price (2014), "The Role of Brands and Mediating Technologies in Assembling Long-Distance Family Practices," Journal of Marketing, 78 (3), 81-101.

Erdem, Tülin (1998), “An Empirical Analysis of Umbrella Branding,” Journal of Marketing Research, 35 (3), 339-51.

Erdem, Tülin and Joffre Swait (1998), "Brand Equity as a Signaling Phenomenon," Journal of Consumer Psychology, 7 (2), 131-57.

Escalas, Jennifer Edson and James Bettman (2005), "Self-Construal, Reference Groups, and Brand Meaning," Journal of Consumer Research, 32 (3), 378-89.

Field, John (2017), Social Capital: Key Ideas, Abingdon, Oxon: Routledge, 3rd edition.

Fine, Seymour H. (1981), The Marketing of Ideas and Social Issues. New York: Praeger.

Fournier, Susan and Claudio Alvarez (2019) "How Brands Acquire Cultural Meaning," Journal of Consumer Psychology, 29 (3), 519-34.

Fournier, Susan and Jill Avery (2011), “The Uninvited Brand,” Business Horizons, 54 (3), 193-207.

Fournier, Susan and Giana M. Eckhardt (2019) "Putting the Person Back in Person-Brands: Understanding and Managing the Two-Bodied Brand," Journal of Marketing Research, 56 (4), 602-19.

Fredette, John, Revital Marom, K. Steiner, and Louis Witters (2012), "The Promise and Peril of Hyperconnectivity for Organizations and Societies," in The Global Information Technology Report 2012. Cologny: World Economic Forum, 113-19.

Gielens, Katrijn and Jan-Benedict E.M. Steenkamp (2019), "Branding in the Era of Digital (Dis)Intermediation," International Journal of Research in Marketing, 36 (3), 367-384

Giesler, Markus (2012), "How Doppelgänger Brand Images Influence the Market Creation Process: Longitudinal Insights from the Rise of Botox Cosmetic," Journal of Marketing, 76 (6), 55-68.

Gneiser, Martin, Julia Heidemann, Mathias Klier, Andrea Landherr, and Florian Probst (2012) "Valuation of Online Social Networks Taking into Account Users' Interconnectedness," Information Systems and EBusiness Management, 10 (1), 61-84.

Goffman, Erving (1959), Presentation of Self in Everyday Life. Garden City, NY: Doubleday Anchor Books. Goldfarb, Avi and Catherine E. Tucker (2011), "Privacy Regulation and Online Advertising," Management Science, 57 (1), 57-71.

Herhausen, Dennis, Stephan Ludwig, Dhruv Grewal, Jochen Wulf, and Marcus Schoegel (2019), “Detecting, 
Preventing, and Mitigating Online Firestorms in Brand Communities," Journal of Marketing, 83 (3), 1-21.

Hewett, Kelly, William Rand, Roland T. Rust, and Harald J. Van Heerde (2016), "Brand Buzz in the

Echoverse," Journal of Marketing, 80 (3), 1-24.

Hoffman, Donna and Thomas Novak (2017), "Consumer and Object Experience in the Internet of Things: An

Assemblage Theory Approach,” Journal of Consumer Research, 44 (6), 1178-1204.

Holt, Douglas B. (2002), "Why Do Brands Cause Trouble? A Dialectical Theory of Consumer Culture and

Branding," Journal of Consumer Research, 29 (1), 70-90.

Holt, Douglas B. (2004), How Brands Become Icons. Cambridge, MA: Harvard Business School Press.

Hoyer, Wayne D., Rajesh Chandy, Matilda Dorotic, Manfred Krafft, and Siddharth S. Singh (2010), "Consumer Cocreation in New Product Development," Journal of Service Research, 13 (3), 283-96.

Hsu, Liwu, Susan Fournier, and Shuba Srinivasan (2016), "Brand Architecture Strategy and Firm Value: How Leveraging, Separating, and Distancing the Corporate Brand Affects Risk and Returns," Journal of the Academy of Marketing Science, 44 (2), 261-80.

Hughes, Christian, Vanitha Swaminathan and Gillian Brooks (2019), "Driving Brand Engagement Through Online Social Influencers: An Empirical Investigation of Sponsored Blogging Campaigns," Journal of Marketing, 83 (5), 78-96.

Ind, Nicholas (1997), The Corporate Brand. London: Palgrave Macmillan.

Janiszewski, Chris and Stijn MJ Van Osselaer (2000), "A Connectionist Model of Brand-Quality

Associations," Journal of Marketing Research, 37 (3), 331-50.

Jardine, Alexander (2019), "P \& G is Ad Age 2019 Marketer of the Year," Advertising Age, December 8, 2019.

Kapferer, Jean-Noël (2012), The New Strategic Brand Management. Sterling, VA: Kogan Page.

Kaplan, Andreas M. and Michael Haenlein (2010), "Users of the World, Unite! The Challenges and Opportunities of Social Media," Business Horizons, 53 (1), 59-68.

Keller, Kevin Lane (1993), "Conceptualizing, Measuring, and Managing Consumer-Based Brand Equity," Journal of Marketing, 57 (1), 1-22.

Keller, Kevin Lane and Donald R. Lehmann (2006), "Brands and Branding: Research Findings and Future Priorities," Marketing Science, 25 (6), 740-59.

Kerrigan, Finola, Douglas Brownlie, Paul Hewer, and Claudia Daza-LeTouze (2011), “'Spinning’ Warhol: Celebrity Brand Theoretics and the Logic of the Celebrity Brand," Journal of Marketing Management, 27 (13/14), 1504-24.

Kotler, Philip and David Gertner (2002), "Country as Brand, Product, and Beyond: A Place Marketing and Brand Management Perspective,” Journal of Brand Management, 9 (4), 249-61.

Kozinets, Robert V. (2014), "Social Brand Engagement: A New Idea," GfK Marketing Intelligence Review, 6 (2), 8-15.

Krishna, Aradhna (2010), Sensory Marketing: Research on the Sensuality of Products. New York: Routledge.

Krishna, Aradhna and Norbert Schwarz (2014), "Sensory Marketing, Embodiment and Grounded Cognition: A Review and Introduction," Journal of Consumer Psychology, 24 (2), 159-68.

Landsman, Vardit and Stefan Stremersch. (2011), "Multihoming in Two-Sided Markets: An Empirical Inquiry in the Video Game Console Industry," Journal of Marketing, 75 (6), 39-54.

Lane, Vicki and Robert Jacobson (1995), "Stock Market Reactions to Brand Extension Announcements: The Effects of Brand Attitude and Familiarity," Journal of Marketing, 59 (1), 63-77.

Levy, Sidney J. (1959), "Symbols for Sale," Reprinted in Brands, Consumers, Symbols, and Research: Sidney J. Levy on Marketing (1999). Thousand Oaks, CA: Sage Publications, 203-12.

Libai, Barak, Ruth Bolton, Marnix S. Bügel, Ko De Ruyter, Oliver Götz, Hans Risselada, and Andrew T. Stephen (2010), "Customer-to-Customer Interactions: Broadening the Scope of Word of Mouth Research," Journal of Service Research, 13 (3), 267-82.

Lovett, Mitchell J., Renana Peres, and Ron Shachar (2013), “On Brands and Word of Mouth,” Journal of Marketing Research, 50 (4), 427-44.

Lucarelli, Andrea and Per Olof Berg (2011), "City Branding: A State-of-the-art Review of the Research

Domain," Journal of Place Management and Development, 4 (1), 9-27.

Lurie, Nicholas H. (2004), "Decision Making in Information-Rich Environments: The Role of Information 
Structure," Journal of Consumer Research, 30 (4), 473-86.

Lynch, John G., Jr., and Dan Ariely (2000), "Wine Online: Search Costs Affect Competition on Price, Quality, and Distribution," Marketing Science, 19 (1), 83-103.

MacInnis, Deborah J. and Valerie S. Folkes (2017), "Humanizing Brands: When Brands Seem to Be Like Me, Part of Me and in a Relationship with Me," Journal of Consumer Psychology, 27 (3), 355-74.

MacInnis, Deborah, Christine Moorman, and Bernard J. Jaworski (1991), "Enhancing and Measuring Consumers' Motivation, Opportunity, and Ability to Process Brand Information from Ads," Journal of Marketing, 55 (4), 32-53.

Madden, Thomas J., Frank Fehle, and Susan Fournier (2006), "Brands Matter: An Empirical Demonstration of the Creation of Shareholder Value through Branding," Journal of the Academy of Marketing Science, 34 (2), 224-35.

Maras, Elliott (2018), "Glossier Engaging Customers by Spurring Interaction, Communication," Retail Customer Experience, https://www.retailcustomerexperience.com/articles/glossier-engaging-customers-byspurring-interaction-communication/, accessed on 12/17/2019.

Martin, Kelly D., Abhishek Borah, and Robert W. Palmatier (2017), "Data Privacy: Effects on Customer and Firm Performance," Journal of Marketing, 81 (1), 36-58.

McCain, Jessica L. and W. Keith Campbell (2018), "Narcissism and Social Media Use: A Meta-Analytic Review," Psychology of Popular Media Culture, 7 (3), 308-27.

Meire, Matthijs, Kelly Hewett, Michel Ballings, V. Kumar, and Dirk Van den Poel (2019), "The Role of Marketer-Generated Content in Customer Engagement Marketing," Journal of Marketing, 83 (6), 21-42.

Melnyk, Valentyna, Kristina Klein, and Franziska Völckner (2012), "The Double-Edged Sword of Foreign Brand Names for Companies from Emerging Countries," Journal of Marketing, 76 (6), 21-37.

Miller, Daniel (2010), The Comfort of Things. Cambridge, UK: Polity.

Mizik, Natalie and Robert Jacobson (2008), "The Financial Value Impact of Perceptual Brand Attributes," Journal of Marketing Research, 45 (1), 15-32.

Morgan, Neil A. and Lopo L. Rego (2009), "Brand Portfolio Strategy and Firm Performance," Journal of Marketing, 73 (1), 59-74.

Morgan, Paul (2010), “Towards a Developmental Theory of Place Attachment," Journal of Environmental Psychology, 30 (1), 11-22.

Morhart, F., Malär, L., Guèvremont, A., Girardin, F., \& Grohmann, B. (2015), "Brand Authenticity: An Integrative Framework and Measurement Scale," Journal of Consumer Psychology, 25(2), 200-218.

Muñiz, Albert M., Jr., and Thomas C. O'Guinn (2001), "Brand Community,” Journal of Consumer Research, 27 (4), 412-31.

Netzer, Oded, Ronen Feldman, Jacob Goldenberg, and Moshe Fresko (2012), "Mine Your Own Business: Market-Structure Surveillance Through Text Mining," Marketing Science, 31 (3), 521-43.

$\mathrm{Ng}$, Irene C.L. and Susan Y.L. Wakenshaw (2017), "The Internet-of-Things: Review and Research Directions," International Journal of Research in Marketing, 34 (1), 3-21.

Nguyen, Hang T. and Malika Chaudhuri (2019), "Making New Products Go Viral and Succeed," International Journal of Research in Marketing, 36 (1), 39-62.

Novak, Thomas P. and Donna L. Hoffman (2019), "Relationship Journeys in the Internet of Things: A New Framework for Understanding Interactions Between Consumers and Smart Objects," Journal of the Academy of Marketing Science, 47 (2), 216-37.

Nysveen, Herbjørn and Per Egil Pedersen (2014), "Influences of Cocreation on Brand Experience," International Journal of Market Research, 56 (6), 807-32.

O'Guinn, Thomas C., Albert M. Muñiz Jr., and Erika Paulson (2018), "Brands and Branding: A Critique of Extant Brand Research and the Need for a Sociological Conception of Brands," in The Oxford Handbook of Consumption, Frederick Wherry and Ian Woodward, eds. New York: Oxford University Press.

O’Guinn, Thomas Clayton, Robin J. Tanner and Ahreum Maeng (2015), “Turning to Space: Social Density, Social Class and the Value of Things in Stores," Journal of Consumer Research, 42;2 (August), 196-213

O’Shea, Dan (2019), “Amazon Sets Up Virtual Furniture Showroom Online,” Retail Dive, https://www.retaildive.com/news/amazon-sets-up-virtual-furniture-showroom-online/545380/, 
accessed on 12/17/2019.

Park, C. Whan, Sung Youl Jun, and Allan D. Shocker (1996), "Composite Branding Alliances: An Investigation of Extension and Feedback Effects," Journal of Marketing Research, 33 (4), 453-66.

Pasquarelli, Adrianne and E. J. Schultz (2018), "Nike is Ad Age's Marketer of the Year for 2018," Advertising Age, (December 3), https://adage.com/article/cmo-strategy/nike-ad-age-s-marketer-year-2018/31579/, accessed on 12/18/2019.

Perren, Rebeca and Robert V. Kozinets (2018), "Lateral Exchange Markets: How Social Platforms Operate in a Networked Economy," Journal of Marketing, 82 (1), 20-36.

Potapov, Dmitriy, Irina Shafranskaya, and Anastasiya Bozhya-Volya (2016), "Happiness and the City: An Empirical Study of the Interaction between Subjective Well-being and City Satisfaction," Journal of Place Management and Development, 9 (3), 313-30.

Putnam, Robert (2000), Bowling Alone: The Collapse and Revival of American Community. New York: Simon and Schuster.

Quan-Haase, Anabel, and Barry Wellman (2005), "Local Virtuality In an Organization: Implications for Community of Practice," Communities and technologies, pp. 215-238. Springer, Dordrecht

Rajavi, Koushyar, Tarun Kushwaha, and Jan-Benedict E.M. Steenkamp (2019), "In Brands We Trust? A MultiCategory and Multi-Country Investigation of Sensitivity of Consumers' Trust in Brands to Marketing-Mix Activities," Journal of Consumer Research, 46 (December), 651-670.

Ramaswamy, Venkat and Kerimcan Ozcan (2016), "Brand Value Co-Creation in a Digitalized World: An Integrative Framework and Research Implications," International Journal of Research in Marketing, 33 (1), 93-106.

Reed, Americus, Mark Forehand, Stefano Puntoni, and Luk Warlop (2012), "Identity-Based Consumer Behavior," International Journal of Research in Marketing, 29 (4), 310-21.

Rego, Lopo L., Matthew T. Billett, and Neil A. Morgan (2009), "Consumer-Based Brand Equity and Firm Risk," Journal of Marketing, 73 (November), 47-60.

Rust, Roland T., Katherine N. Lemon, and Valarie A. Zeithaml (2004), "Return on Marketing: Using Customer Equity to Focus Marketing Strategy," Journal of Marketing, 68 (1), 109-27.

Saini, Yvonne K., and John G. Lynch Jr. (2016) "The Effects of the Online and Offline Purchase Environment on Consumer Choice of Familiar and Unfamiliar Brands." International Journal of Research in Marketing, 33 (3), 702-705.

Schmitt, Bernd (2012), “The Consumer Psychology of Brands,” Journal of Consumer Psychology, 22 (1), 7-17. Schmitt, Bernd, J. Joško Brakus, and Lia Zarantonello (2015), "From Experiential Psychology to Consumer Experience," Journal of Consumer Psychology, 25 (1), 166-71.

Schmitt, Bernd (2019), "From Atoms to Bits and Back: A Research Curation on Digital Technology and Agenda for Future Research," Journal of Consumer Research, 46 (4), 825-832.

Schwartz, Barry (2004), "The Paradox of Choice: Why More Is Less.” New York: Ecco.

Sherman, Jeffrey W., Bertram Gawronski, and Yaacov Trope, eds. (2014), Dual-Process Theories of the Social Mind. New York: The Guilford Press.

Simões, Dora, Sandra Filipe, and Belem Barbosa (2019), "An Overview on IoT and Its Impact on Marketing," in Smart Marketing with the Internet of Things, Simões, Dora, Sandra Filipe, and Belem Barbosa, eds. Hershey, PA: IGI Global, 1-20.

Simonin, Bernard L. and Julie A. Ruth (1998), "Is a Company Known by the Company It Keeps? Assessing the Spillover Effects of Brand Alliances on Consumer Brand Attitudes," Journal of Marketing Research, 35 (1), $30-42$.

Stahl, Florian, Mark Heitmann, Donald R. Lehmann, and Scott A. Neslin (2012), "The Impact of Brand Equity on Customer Acquisition, Retention, And Profit Margin," Journal Of Marketing, 76(4), 44-63.

Steenkamp, Jan-Benedict E.M. (2017), Global Brand Strategy: World-Wise Marketing in the Age of Branding. New York: Palgrave Macmillan.

Steenkamp, Jan-Benedict E.M. (2019), "Global Versus Local Consumer Culture: Theory, Measurement, and Future Research Directions," Journal of International Marketing, 27 (1), 1-19.

Steenkamp, Jan-Benedict E.M. (2020), "Building Strong Nation Brands," International Marketing Review, 37, 
forthcoming.

Steenkamp, Jan-Benedict E.M. and Inge Geyskens (2006), "How Country Characteristics Affect the Perceived Value of Web Sites," Journal of Marketing, 70 (July), 136-50.

Suh, Ayoung (2013), "The Influence of Self-Discrepancy Between The Virtual And Real Selves In Virtual Communities," Computers in Human Behavior, 29(1), 246-256.

Swaminathan, Vanitha and Christine Moorman (2009) "Marketing Alliances, Firm Networks, and Firm Value Creation," Journal of Marketing, 73 (5), 52-69.

Swaminathan, Vanitha, Karen L. Page, and Zeynep Gürhan-Canli (2007), “"My’ Brand or 'Our” Brand: The Effects of Brand Relationship Dimensions and Self-construal on Brand Evaluations," Journal of Consumer Research, 34 (2), 248-59.

Tavassoli, Nader T., Alina Sorescu, and Rajesh Chandy (2014), "Employee-Based Brand Equity: Why Firms with Strong Brands Pay Their Executives Less," Journal of Marketing Research, 51 (6), 676-90.

Taylor, Meggen (2018), "Proven: This Female-Led Tech Start-Up Is Using AI To Customize Skincare," Forbes, https://www.forbes.com/sites/meggentaylor/2018/11/07/proven-this-female-led-tech-start-up-is-using-ai-tocustomize-skincare/\#2f8ad551744f, accessed on 12/18/2019

Tellis, Gerard J., Deborah J. MacInnis, Seshadri Tirunillai, and Yanwei Zhang (2019), "What Drives Virality (Sharing) of Online Digital Content? The Critical Role of Information, Emotion, and Brand Prominence," Journal of Marketing, 83 (4), 1-20.

Thomas, Meredith and Thomas C. O’Guinn (2019), "Buying and Giving Community,” Working Paper, University of Wisconsin-Madison.

Thompson, Craig J. and Eric Arnould (2005), “Consumer- Culture-Theory - 20 Years of Research,” Journal of Consumer Research, 31 (March), 868-82.

Thompson, Craig J., William B. Locander, and Howard R. Pollio (1989), "Putting Consumer Experience Back into Consumer Research: The Philosophy and Method of Existential-Phenomenology," Journal of Consumer Research, 16, 133-46.

Thompson, Craig J., Aric Rindfleisch, and Zeynep Arsel (2006), "Emotional Branding and the Strategic Value of the Doppelgänger Brand Image," Journal of Marketing, 70 (January), 50-64.

Thompson, Debora V. and Prashant Malaviya (2013), "Consumer-Generated Ads: Does Awareness of Advertising Cocreation Help or Hurt Persuasion?” Journal of Marketing, 77 (3), 33-47.

Thomson, Matthew. (2006) "Human Brands: Investigating Antecedents to Consumers' Strong Attachments to Celebrities," Journal of Marketing, 70 (3), 104-19.

Thomson, Matthew, Deborah J. MacInnis, and C. Whan Park (2005), “The Ties That Bind: Measuring the Strength of Consumers' Emotional Attachments to Brands," Journal of Consumer Psychology, 15 (1), 77 91.

Torelli, Carlos J. and Rohini Ahluwalia (2011), "Extending Culturally Symbolic Brands: A Blessing or a Curse?" Journal of Consumer Research, 38 (5), 933-47.

Turkle, Sherry (2017), Alone Together: Why We Expect More from Technology and Less from Each Other. London: Hachette UK.

Tybout, Alice M. and Tim Calkins (2019), Kellogg on Branding in a Hyper-Connected World. Hoboken, NJ: John Wiley \& Sons.

Van Alstyne, Marshall W., Geoffrey G. Parker, and Sangeet Paul Choudary (2016), "6 Reasons Platforms Fail," Harvard Business Review Digital Articles, March, 2-6, https://hbr.org/2016/03/6-reasons-platforms-fail .

Vargo, Stephen L. and Robert F. Lusch (2004), “Evolving to a New Dominant Logic for Marketing," Journal of Marketing, 68 (January), 1-17.

Völckner, Franziska and Henrik Sattler (2006), "Drivers of Brand Extension Success,” Journal of Marketing, 70 (2), 18-34.

Wang, Pengyuan, Guiyang Xiong, and Jian Yang (2019), "Serial Position Effects on Native Advertising Effectiveness: Differential Results Across Publisher and Advertiser Metrics," Journal of Marketing, 83 (2), 82-97.

Wang, Helen Si, Charles H. Noble, Darren W. Dahl, and Sungho Park (2019), "Successfully Communicating a Cocreated Innovation," Journal of Marketing, 83 (4), 38-57. 
Warren, Caleb, Rajeev Batra, Sandra Maria Correia Loureiro, and Richard P. Bagozzi (2019), "Brand Coolness," Journal of Marketing, 83 (5), 36-56.

Wernerfelt, Birger (1988), "Umbrella Branding as a Signal of New Product Quality: An Example of Signaling by Posting a Bond," RAND Journal of Economics, 19 (3), 458-66.

Wiles, Michael A., Neil A. Morgan, and Lopo L. Rego (2012), "The Effect of Brand Acquisition and Disposal on Stock Returns," Journal of Marketing, 76 (1), 38-58.

Wipperfürth, Allen (2005), Brand Hijack: Marketing without Marketing, New York: Portfolio.

Wu, Jintao, Junsong Chen, and Wenyu Dou (2017), "The Internet of Things and Interaction Style: The Effect of Smart Interaction on Brand Attachment," Journal of Marketing Management, 33 (1/2), 61-75.

Yadav, Manjit S. and Paul A. Pavlou (2014), "Marketing in Computer-Mediated Environments: Research Synthesis and New Directions," Journal of Marketing, 78 (1), 20-40.

Zenker, Sebastian and Erik Braun (2010), "The Place Brand Centre-A Conceptual Approach for the Brand Management of Places," in 39th European Marketing Academy Conference. Copenhagen: European Marketing Academy, 1-8.

Zhou, Zhou and Marshall Van Alstyne (2019), "Platform Valuation: Profit or User Base?" Working paper, Boston University, https://pdfs.semanticscholar.org/e543/e89ed8482d231a5fd6e552afdb346821dc12.pdf, accessed on 12/18/2019. 
TABLE 1 Rethinking the Roles and Functions of Brands: New Research Directions

\begin{tabular}{|c|c|c|}
\hline $\begin{array}{l}\text { Extant } \\
\text { Research }\end{array}$ & Future Research & Research Questions \\
\hline $\begin{array}{l}\text { Brands as } \\
\text { quality signals } \\
\text { sent by firms }\end{array}$ & $\begin{array}{l}\text { Brand meaning and } \\
\text { quality perceptions } \\
\text { crafted by market } \\
\text { feedback. Weakened } \\
\text { role of firm } \\
\text { communications in } \\
\text { shaping brand signals }\end{array}$ & $\begin{array}{l}\text { - Under what conditions do consumers still trust firm communications about brands (vs. information } \\
\text { intermediaries such as Yelp, TripAdvisor, and Rotten Tomatoes)? } \\
\text { - What is the impact of firm-generated versus marketplace-generated brand information on brand } \\
\text { trust? } \\
\text { - How can firms manage a brand communication process that faces significant signal interference? } \\
\text { - How should firms respond to signal interference: what types of message content, form, and media } \\
\text { placement have the best chance of reducing and counterbalancing potentially undesirable external } \\
\text { brand signals? }\end{array}$ \\
\hline $\begin{array}{l}\text { Brands as } \\
\text { mental cues }\end{array}$ & $\begin{array}{l}\text { Brand information } \\
\text { processing models that } \\
\text { account for } \\
\text { information being } \\
\text { conveyed in a } \\
\text { multisensory way }\end{array}$ & $\begin{array}{l}\text { - How can researchers best conceptualize brand information processing when consumers deal with } \\
\text { high volume and velocity of information? } \\
\text { - What is the role of sensorial brand information in models of information processing? } \\
\text { - How are brand meanings constructed under high volume and velocity of information? Can they be } \\
\text { more easily manipulated? Under what conditions? } \\
\text { - What is the balance of voluntary versus involuntary attention in a context of information overload, } \\
\text { and what type of cues can brands use to elicit voluntary attention? } \\
\text { - What are the structure and balance of text, image, and sound that can make a brand message stand } \\
\text { out in a context of information overload? }\end{array}$ \\
\hline $\begin{array}{l}\text { Brands as tools } \\
\text { of identity } \\
\text { expression and } \\
\text { as relationship } \\
\text { partners }\end{array}$ & $\begin{array}{l}\text { Brands as tools of } \\
\text { multifaceted identity } \\
\text { expression and goal } \\
\text { achievement }\end{array}$ & $\begin{array}{l}\text { - Can brand associations be constructed and revised to allow for a more flexible view of identity? } \\
\text { - Does a more flexible meaning lead to stronger long-term brand performance? } \\
\text { - Do consumers prefer that brands have a well-defined meaning that helps them anchor and retrieve } \\
\text { one particular facet of their identity, or are they drawn more to brands with flexible meanings that } \\
\text { accommodate a broader range of self-expression? } \\
\text { - How do social groups leverage brands to help them achieve their social goals? } \\
\text { - How can the strength of brand relationships be maintained and increased under information } \\
\text { overload? } \\
\text { - How can brand anthropomorphism powered by artificial intelligence contribute to brand choice, } \\
\text { loyalty, and trust and to building stronger brand relationships? }\end{array}$ \\
\hline $\begin{array}{l}\text { Brands as } \\
\text { cultural icons }\end{array}$ & $\begin{array}{l}\text { Brands as containers } \\
\text { of socially constructed } \\
\text { meaning }\end{array}$ & $\begin{array}{l}\text { - How do different target segments respond to brands capitalizing on or opposing rising social trends? } \\
\text { - How can researchers conceptualize brands as purpose-driven entities? } \\
\text { - How can brand conversations and engagement foster greater social connections? } \\
\text { - What are the facets, determinants, and consequences of "social brand engagement" or the propensity } \\
\text { of consumers to engage in meaningful connections using brands? And will this hurt the brand? } \\
\text { - How does social brand engagement play out for global brands in a world of diverging values and }\end{array}$ \\
\hline
\end{tabular}




\begin{tabular}{|c|c|c|}
\hline & & political and social fragmentation, as well as antagonism? \\
\hline $\begin{array}{l}\text { Brands as } \\
\text { individual } \\
\text { entities or dyad } \\
\text { partners }\end{array}$ & $\begin{array}{l}\text { Brands as architects of } \\
\text { value in networks }\end{array}$ & $\begin{array}{l}\text { - What strategies should brands adopt to enhance the effective functioning of the brand ecosystem? } \\
\text { - How can brands establish successful partnerships with other network participants, and what is the } \\
\text { impact of platform design on maximizing positive and minimizing negative spillovers from partner } \\
\text { brands? } \\
\text { - What are the main drivers of satisfaction with the user experience on brand networks, and how do } \\
\text { consumers derive utility from a branded network? } \\
\text { - How can brands establish themselves into entities that can protect consumers from harmful content } \\
\text { or products available on networks? }\end{array}$ \\
\hline $\begin{array}{l}\text { Brands as tools } \\
\text { of individual } \\
\text { self-expression }\end{array}$ & $\begin{array}{l}\text { Brands as catalysts of } \\
\text { communities }\end{array}$ & $\begin{array}{l}\text { - How can branded entities facilitate the emergence of an online branded community, and what is the } \\
\text { best way to enable, support, and help expand it? } \\
\text { - What are the mechanisms through which online brand communities create value for various } \\
\text { stakeholders? } \\
\text { - What are the nature and quality of human interactions in the online space, and how can brand } \\
\text { communities positively assuage loneliness and social isolation? }\end{array}$ \\
\hline $\begin{array}{l}\text { Brands as } \\
\text { neutral entities }\end{array}$ & $\begin{array}{l}\text { Brands as arbiters of } \\
\text { controversy }\end{array}$ & $\begin{array}{l}\text { - How does brands' participation in controversy (political, social) affect their customer base? } \\
\text { - How can brands maintain their authenticity and align their associations with social issues that are } \\
\text { shaping current values and perceptions in society? } \\
\text { - What are some new metrics (e.g., polarization, controversy score) that can capture how to track the } \\
\text { nature of conversation about brands in controversial settings? }\end{array}$ \\
\hline $\begin{array}{l}\text { Brands as } \\
\text { guarantors of } \\
\text { quality }\end{array}$ & $\begin{array}{l}\text { Brands as stewards of } \\
\text { consumer data privacy }\end{array}$ & $\begin{array}{l}\text { - Should brands establish an association with strong guardianship of customer data, or would it be } \\
\text { easier to partner with brands that have already built such associations? } \\
\text { - What type of safeguards can be established at every level of society to allow individuals and social } \\
\text { groups to interact with brands and to provide them with sufficient information to strengthen the brand } \\
\text { relationship, without adverse consequences, such as identity theft, loss of privacy, or economic } \\
\text { losses? }\end{array}$ \\
\hline
\end{tabular}


TABLE 2 Rethinking Brand Value Creation and Cocreation: New Research Directions

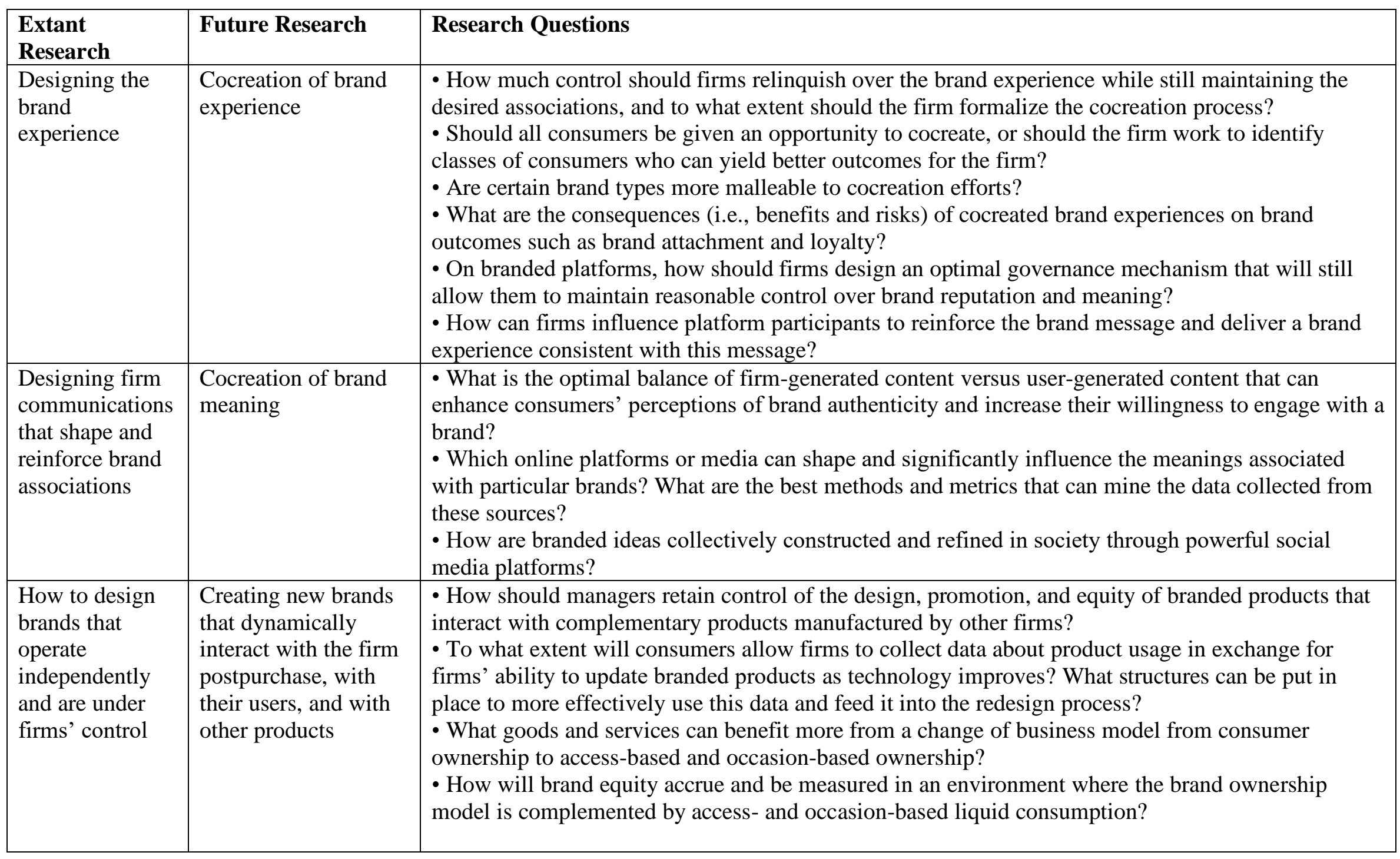




\begin{tabular}{|c|c|c|}
\hline $\begin{array}{l}\text { Brand positioning } \\
\text { and message } \\
\text { controlled by } \\
\text { firm }\end{array}$ & $\begin{array}{l}\text { Brand message as an } \\
\text { output of multimedia } \\
\text { online consumer } \\
\text { communications }\end{array}$ & $\begin{array}{l}\text { - What types of stakeholders exert more influence on brand communications, and what metrics best } \\
\text { capture this influence? } \\
\text { - How can brand communication by outside stakeholders be incorporated into firms' brand } \\
\text { strategies, and should it be? } \\
\text { - What are the best metrics to mine and extract insights from multimedia social media data related to } \\
\text { brands? How can static and video images and sounds be mined for branding insights? }\end{array}$ \\
\hline $\begin{array}{l}\text { Brand crises } \\
\text { limited to product } \\
\text { failures }\end{array}$ & $\begin{array}{l}\text { Brand crises } \\
\text { resulting from the } \\
\text { behavior of a } \\
\text { broader class of } \\
\text { stakeholders }\end{array}$ & $\begin{array}{l}\text { - What are the best governance and response mechanisms that can minimize the loss of brand equity } \\
\text { in the event of stakeholder nefarious actions? } \\
\text { - How much blame do consumers attribute to firms in brand crises depending on which stakeholders } \\
\text { cause the harm, and how does this influence their brand relationship going forward? }\end{array}$ \\
\hline $\begin{array}{l}\text { Brands as } \\
\text { identifiers of } \\
\text { static } \\
\text { consumption } \\
\text { objects }\end{array}$ & $\begin{array}{l}\text { Brands as identifiers } \\
\text { of intelligent, } \\
\text { interactive, and } \\
\text { networked devices. }\end{array}$ & $\begin{array}{l}\text { - How can artificial and virtual reality create unique brand experiences for consumers before, during, } \\
\text { and after purchase? } \\
\text { - How should firms brand and manage nontangible information and nonhuman, but humanlike, } \\
\text { autonomous agents? } \\
\text { - What is the best way to design branded experiences delivered with the help of artificial intelligence } \\
\text { and robots, while keeping safety and privacy concerns in mind? }\end{array}$ \\
\hline $\begin{array}{l}\text { Brand value } \\
\text { measured as } \\
\text { customer-based } \\
\text { brand equity, } \\
\text { price premium, or } \\
\text { change in stock } \\
\text { market value }\end{array}$ & $\begin{array}{l}\text { Develop new } \\
\text { metrics of } \\
\text { stakeholder value } \\
\text { that can take into } \\
\text { account the blurred } \\
\text { ownership of brands }\end{array}$ & $\begin{array}{l}\text { - Is it possible to develop an internationally recognized, standardized way to measure "traditional" } \\
\text { brand equity? } \\
\text { - How can the marketing academic community contribute to putting brand value on the balance } \\
\text { sheet? } \\
\text { - How can the value of platform brands that derive their value primarily from networks be } \\
\text { measured? } \\
\text { - What are the best metrics and time horizons to assess stakeholder value? } \\
\text { - Can firms increase value for various stakeholders without damaging shareholder value? }\end{array}$ \\
\hline
\end{tabular}


TABLE 3 Rethinking the Boundaries of Branding: New Research Directions

\begin{tabular}{|c|c|c|}
\hline $\begin{array}{l}\text { Branded entities } \\
\text { studied in prior } \\
\text { research }\end{array}$ & $\begin{array}{l}\text { Branded } \\
\text { entities in need } \\
\text { of further study }\end{array}$ & Research Questions \\
\hline \multirow{4}{*}{$\begin{array}{l}\text { Commercial } \\
\text { product and } \\
\text { service brands; } \\
\text { celebrity brands; } \\
\text { corporate brands; } \\
\text { place brands in } \\
\text { the tourism } \\
\text { literature }\end{array}$} & Idea brands & $\begin{array}{l}\text { - How do branded ideas emerge and spread? What are the factors impacting the diffusion of positively- } \\
\text { versus negatively-valenced ideas? } \\
\text { - How are associations with branded ideas formed and what is the role of opinion leaders? How do } \\
\text { mixed societal responses contribute to shaping these ideas brands and what constituencies play a greater } \\
\text { role in refining the idea brand message? } \\
\text { - How can the authenticity and strength of idea brands be assessed and measured and what are the } \\
\text { factors that contribute to this authenticity? }\end{array}$ \\
\hline & Person brands & $\begin{array}{l}\text { - How can non-celebrities build a person brand with clear brand associations that can help them attain } \\
\text { specific personal or professional goals? } \\
\text { - What are the psychological consequences that consumers can experience from managing their personal } \\
\text { brand, including the potential for higher narcissism, self-promotion focus, and individualistic } \\
\text { tendencies? }\end{array}$ \\
\hline & Place brands & $\begin{array}{l}\text { - How can places promote their brands without increasing the conflict between various classes of } \\
\text { stakeholders, such as the residents and visitors of a city? } \\
\text { What are the implications of social density and social class perceptions for place brands? } \\
\text { - How can place brands mitigate the negative consequences associated with unfavorable social, } \\
\text { economic and climate changes? }\end{array}$ \\
\hline & $\begin{array}{l}\text { Organizations as } \\
\text { brands }\end{array}$ & $\begin{array}{l}\text { - How can organizations create and deliver a purpose within society that aligns well with their brand } \\
\text { associations and mission? } \\
\text { - How can organizations manage brand associations faced with an increasingly large set of relevant } \\
\text { stakeholders that can contribute to these associations, from consumers and employers, to activist } \\
\text { investors and other organizations? } \\
\text { - What drives brand perceptions for organizations that serve the common good and what could disrupt } \\
\text { the branding efforts of infamous organizations? }\end{array}$ \\
\hline
\end{tabular}




\section{FIGURE 1}

\section{Ownership of Branded Entities and Changes in the Branding Landscape}

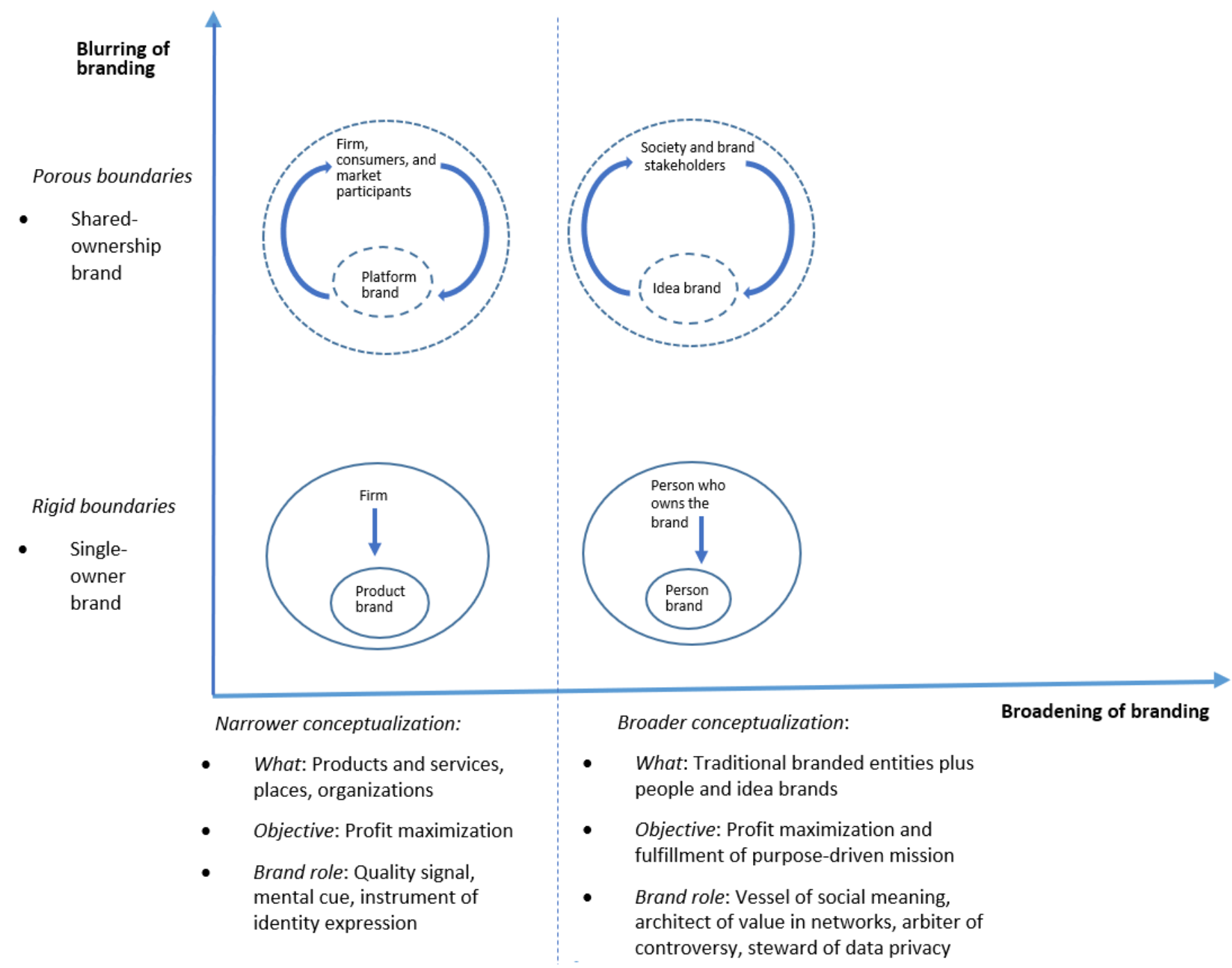

Notes: The figure depicts interactions between various types of brands and their owners and primary stakeholders. Inner circles represent a specific type of brand; outer circles encompass the brand owners or main stakeholders. Dotted circles indicate more porous boundaries of brand ownership. We have labeled the brand owner and used arrows to illustrate whether the relationship between the brand and its owner/stakeholders is unidirectional or dynamic. 